\title{
Do Physically Stronger Males Prevail in Non-Physical Conflicts?
}

June 2020

\author{
Dan Nguyen \\ Department of Economics and Business Economics, Aarhus University \\ Michael Bang Petersen \\ Department of Political Science, Aarhus University \\ Julia Nafziger \\ Department of Economics and Business Economics, Aarhus University
}

Alexander K. Koch

Department of Economics and Business Economics, Aarhus University

\begin{abstract}
Author Note
Address correspondence to Alexander Koch, Department of Economics and Business Economics, Aarhus University, Fuglesangs Allé 4, 8210 Aarhus V, Denmark. E-mail: akoch@econ.au.dk
\end{abstract}




\begin{abstract}
Among non-human animals, a key strategy to resolve conflicts without fighting relies on assessing relative fighting ability on the basis of physical cues such as size and strength. Recent studies hypothesize that the human mind also contains mechanisms for spontaneously coordinating conflict behavior on the basis of difference in physical strength, even if strength is not rationally relevant to the conflict. We provide the first direct, experimental test of the existence of such mechanisms. We do so by applying a non-physical, anonymous, economic game - the war-ofattrition - in which male contestants compete by means of perseverance to win a monetary prize. While initial studies provided some support for the prediction, the final well-powered and preregistered study failed to support the prediction. Overall, we interpret our findings as evidence against the hypothesis that the human mind attributes relevance to physical factors that are irrelevant for the actual resolution of a conflict. We discuss implications for existing findings in the field and provide directions for further research.
\end{abstract}

Keywords: upper-body strength; asymmetric war of attrition; behavioral economics; evolutionary mismatches 
Conflict pervades the human condition: nations go to war, co-workers compete for promotions, and neighbors quarrel over fences. Any well-functioning social group consequently requires strategies for conflict resolution among its members, where conflict resolution is understood here broadly as the strategies that parties employ to avoid or terminate a conflict. ${ }^{1}$ Throughout the animal world, strikingly similar conflict-resolution strategies exist (De Waal, 2000). One of the best-validated models of behavioral ecology - the Asymmetric War of Attrition (AWA) - captures how animals in competition over resources coordinate to avoid costly fighting (Maynard Smith \& Parker, 1976; Hammerstein \& Parker, 1982). Because a number of easy-to-determine physical differences between animals affect their fighting ability, e.g., general size of body, antlers, or horns (Arnott \& Elwood, 2009), mutual assessment of these features allows contestants to forecast who would prevail in a physical fight and coordinate their behavior accordingly without resorting to physical aggression (Parker, 1974). Sexually selected physical differences that are not directly related to fighting ability, but signal rank and dominance (such as the silver crest of mature silver back gorillas) can provide additional information for conflict-resolution (Grueter et al., 2015).

The AWA-model was validated in species as diverse as ants, flies, fish, spiders, butterflies, crickets, chameleons, deer, and elephants (Hardy \& Briffa, 2013). Prior studies also suggest that corresponding strategies may exist in human males, the more aggressive and conflict-prone sex (Daly \& Wilson, 1988; Sell et al., 2012). These previous studies have focused on upper-body strength, which has been reliably associated with fighting ability (Puts, 2010; Sell et al., 2009a), and they have provided tentative evidence for a role of upper-body strength in human conflict

\footnotetext{
${ }^{1}$ Conflict resolution means quite different things to different people and disciplines. For example, for legal scholars the court system and legal norms would be central. Military strategists might emphasize deterrence and perhaps even the option of a first strike against a potential enemy to prevent a larger confrontation. People engaged in peace talks, in contrast, may think of conflict resolution not merely as ceasing a conflict but as removing the underlying causes for conflict.
} 
behavior in a number of ways: humans are highly adept at judging males' upper-body strength (Sell et al., 2009a, 2009b, 2010); preverbal infants and children use cues of fighting ability, such as size differences, to predict conflict outcomes (Thomsen et al., 2011; Pietraszewski \& Shaw, 2015); computer gamers are sensitive to relative fighting abilities of the avatars they operate (DeScioli \& Wilson, 2011); physical strength in males correlates with self-reported measures of both aggressiveness and conflict success (Sell et al., 2009a, Archer \& Thanzami, 2007; Price et al., 2012).

While many of the studies cited above are explicitly grounded in the AWA-model, they have not provided tests among humans that are directly comparable to the tests done with nonhuman animals. Part of the reason may be conceptual. Thus, many human-based studies focus on how higher fighting ability is related to higher levels of motivations to aggressively escalate conflicts in zero-sum settings (see Thomsen, 2020). ${ }^{2}$ For individuals with high fighting ability, the costs of physical aggression are lower and, hence, they are more likely to reap benefits from using aggression when conflict is unavoidable, as is the case in zero-sum relationships. Accordingly, prior studies on humans have focused on the effect of absolute upper-body strength on (selfreported) behavioral traits related to self-assertion and aggression. The AWA-model, however, was originally built to understand how cues of fighting ability are used among animals for mutual benefit to coordinate - without fighting - on who wins and who loses. Accordingly, the AWAmodel and, the tests among non-human animals, have focused on how the behavioral states

\footnotetext{
${ }^{2}$ It is relevant to note that an orientation towards zero-sum conflict is not universally present in past studies on humans. For example, Sell et al. (2009) focus on the relationship between upper-body strength and anger in human males and argue explicitly that this relationship extends beyond zero-sum contexts: "It is worth emphasizing that, for humans at least, anger organizes behavior in both cooperative and zero-sum relationships." (Sell et al., 2009: 15074).
} 
involved in a conflict are flexibly modulated by the relative strength of contestants. Despite more than an a decade of past research on the association between aggression and upper-body strength in human males, this implies that there is still a dearth of knowledge regarding whether the kernel of the AWA-model of conflict resolution among animals applies to humans: Are humans influenced by cues to relative upper-body strength such that actual conflicts are intuitively resolved in favor of the contestant most likely to prevail if the conflict escalated into a physical confrontation?

It is possible to differentiate between a strong and a weak version of this hypothesis. The weak version entails that humans spontaneously regulate their conflict behavior on the basis of relative upper-body strength in situations where upper-body strength is rationally relevant. The strong version, in contrast, suggests that the imprints of an evolutionary history with strengthbased conflict implies that the human mind by default assumes that upper-body strength is relevant, even if this is not the case (sometimes referred to as the misapprehension or mismatch hypothesis, Hagen \& Hammerstein, 2006; Li et al., 2018).

Prior studies have produced significant evidence in favor of the weak version of the AWA hypothesis. For example, Pietraszewski and Shaw (2015) presented children with conflict vignettes and found that children's expectations of who wins the conflict followed the logic of the weak version of the AWA model (see also Thomsen et al. 2011). If we interprete payoff-relevant advantages more broadly to include, for example cost advantages, the weak version of the AWAmodel is also supported by some studies that we review below. More indirect evidence comes from anthropological studies. A famous example is Chagnon’s (1983) description of dyadic conflicts in the Yanomamö tribal society. Contestants initially can assess relative strength through shouting 
matches, chest pounding, and side slapping duels, which allow them to stop conflict when a likely winner can be predicted instead of always escalating into violent fight.

In contrast, there is much less evidence in favor of the strong version of the AWA hypothesis. Nonetheless, this version is of particular interest, because physical strength often does not confer an objective advantage in modern day interactions. For example, labor market earnings increase with height. Yet, the height premium cannot be explained in terms of productivity advantages (Persico et al., 2004; Case \& Paxson, 2008). The mismatch between ancestral and modern environments that evolutionary psychology highlights could help understand why variation in handgrip strength explains much of the height premium (Böckerman et al., 2010; Lundborg et al., 2014). Moreover, strong version of the AWA hypothesis would be consistent with work that has found associations between upper-body strength in males and their political attitudes. For example, males higher in upper-body strength are more likely to support unequal distribution of resources (e.g., Petersen \& Laustsen, 2011), have more self-interested political attitudes (Petersen et al., 2012) and support militarism (Sell et al., 2009; Sell et al., 2017). Sell et al. (2019: 15077) phrases the strong hypothesis thus: "It would be delusional in the modern world to think that your personal strength determines - or even influences - how effective your nation's military will be in a war. Yet our subjects' strength predicted their attitudes toward military action. This is exactly what one would expect if assessments about the use of coalitional force by the state—an evolutionary anomaly — are generated, at least in part, by mechanisms that evolved for assessing the success of coalitional force by small groups of which one is a member." Similarly, Petersen et al. (2013: 1102) writes: "...physical strength is objectively irrelevant to the personal payoffs of particular distributional schemes at the national level (...) Yet our results demonstrate that physically weak males are more reluctant than physically strong males to assert their self-interest-just as if 
disputes over national policies were a matter of direct physical confrontation among small numbers of individuals, rather than abstract electoral dynamics among millions."

As much of the research that brings an evolutionary perspective to conflict behavior in humans is inspired by the AWA-model, we contend that the original version of this model is a natural starting point for experimental research. We test the strong version of the AWA-model in an experiment where anonymous participants interact in a non-physical conflict game - the warof-attrition - where two contestants compete over a prize. The winner is the opponent who persists longest. Persisting comes at a cost that rises with contest duration. From an objective perspective, the contests are symmetric because the induced cost of persisting and the benefit of winning are the same for both contestants and independent of their physical strength. The experimental contest, however, is set up to investigate if participants operate under a subjective assumption that greater relative strength translates into an advantage in conflict situations.

Building on a validation of the stimulus materials (Study 1), our main studies (Studies 2 and 3) employ two experimental treatments. In the first, the Mutual Assessment Treatment, participants mutually assessed physical differences before competing in a war-of-attrition game. If participants intuitively assume that greater relative strength translates into an advantage in conflict situations, the weaker participant should be most likely to withdraw, and he should be quicker to withdraw the easier differences in strength are detected, that is, the larger the strength asymmetry (Parker, 1974). Study 2 compares this with the second treatment, the Self-Assessment Treatment, in a between-subject design. The latter treatment included no prior assessment of mutual physical differences. Thus, if conflicts are spontaneously resolved on the basis of in strength, the above hypotheses should hold in the Mutual Assessment Treatment but should not be 
replicable in the Self-Assessment Treatment, where participants could not adjust their strategies to strength differences. Study 4 investigates possible psychological mechanisms for the findings in Study $2 .^{3}$

The mathematical structure of the AWA-model was previously applied to human conflicts such as competition between firms, military arms races, and strikes (see Hörisch \& Kirchkamp, 2010). A number of lab experiments induced differences in costs of persisting, or other asymmetries among players that have direct payoff consequences in the contest, and tested whether these differences affect players' strategies in the way predicted by game theoretic models (for a survey see Dechenaux et al. 2015). Most closely related to our work is the study by Oprea et al. (2013). Participants faced either a narrow or a wide dispersion in the monetary cost of persisting. They find that two-player contests end more quickly in the wide dispersion treatment and that greater cost differences increase the likelihood that the subject with lower cost wins the contest. Hence, consistent with a weak version of the AWA-model, these studies suggest that players do indeed integrate payoff-relevant factors in their decisions. In contrast, we test the strong version of the AWA-model by considering whether payoff-irrelevant asymmetries among players in physical strength spill over into a symmetric war of attrition, so that the game is played as if it was an asymmetric war of attrition where relative physical strength mattered.

\section{Study 1: Creating Stimulus Materials}

To isolate the effect of strength, we required stimulus materials that reliably transfer information about the strength of an individual while retaining anonymity. We assessed the validity of our

\footnotetext{
${ }^{3}$ Studies are numbered in the order discussed. Study 3 actually ran before Study 4 . The data and Stata do file are available from Harvard Dataverse, https://doi.org/10.7910/DVN/8AEAS1/N9YQBQ,
} 
stimulus, the picture of a body silhouette, by showing pictures of male body silhouettes to participants and asking them, for each picture, to rate the physical strength of the person shown.

\section{Methods}

50 male participants (age: $M=22.84, S D=1.83$ ) were recruited on the Aarhus University campus and compensated with a coffee voucher. They were photographed, had their physical measures taken, and completed a questionnaire (see ESM). Photographs were edited to only reveal the body silhouette of the target (Figure 1). Additionally, 200 male participants were recruited through a Qualtrics Panel from the USA (age: $M=26.68, S D=1.73$ ) and paid 5 US dollars for completing an online survey. For each body picture, they assessed separately physical strength/physical attractiveness on 7-point Likert scales ( 1 = Very weak/Homely and 7 = Very strong/Handsome). We obtained 5,000 unique ratings of physical strength on the body silhouette pictures for the 50 targets and assessed rater accuracy following the procedure of Sell et al. (2009b).

Fig. 1. Examples of body silhouettes used in the Mutual Assessment Treatment
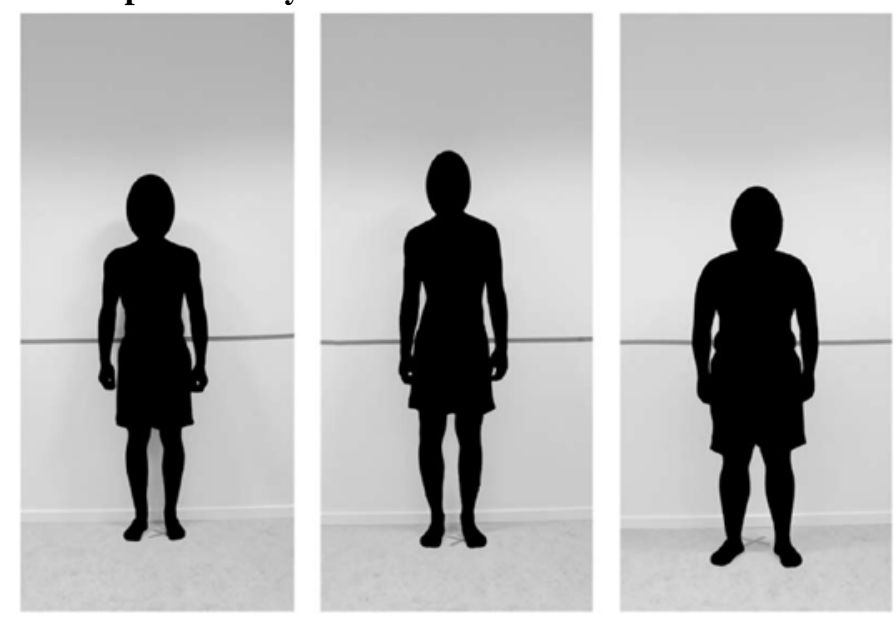


\section{Results}

We find that strangers' rating of strength from body silhouettes of other men strongly correlated with the actual physical strength of those shown, both when considering the average rating of strength for each picture $(r=.55, p<.001, N=50)$ and when regressing standardized actual strength on standardized individual ratings $(\beta=.17, p<.001, N=5,000)$.

\section{Studies 2 and 3: Strength and Conflict-Resolution in the War-of-Attrition Game}

We use the war-of-attrition game to test the key hypotheses that a greater asymmetry in upperbody strength between contestants should (i) decrease the duration of the contest and (ii) increase the probability that the stronger contestant prevails in the Mutual Assessment Treatment. In the Self-Assessment Treatment, where no information about the opponent is available, these effects should not exist. We describe our original study (Study 2) side by side with the pre-registered ${ }^{4}$ replication study (Study 3).

\section{Methods}

Study 2. 66 male participants (age: $M=22.35, S D=2.56$ ) were recruited to "an economic experiment” at the behavioral laboratory facilities of Aarhus University. Lacking a priori evidence on likely effect sizes, we aimed for at least 100 contests in each treatment. To increase power to detect the main effects, we oversampled the main treatment, the Mutual Assessment Treatment ( $\mathrm{N}$ = 42, 205 contests), relative to the Self-Assessment Treatment $(\mathrm{N}=24,106$ contests).

\footnotetext{
${ }^{4}$ Available at osf.io/emfhx
} 
Study 3 aimed to replicate the main findings of Study 2. Based on a power calculation that used as input data from Study 2 (see ESM), 103 male participants (age: $M=25.49, S D=9.60$ ) were recruited $^{5}$ to participate in the Mutual Assessment Treatment ( $\mathrm{N}=103,651$ contests). The unit of analysis is a single round of the war-of-attrition game between two participants.

Each study consisted of two parts. In the first part, participants had their pictures taken and edited to reveal only the body silhouette, using the same procedures as in Study 1. To avoid experimenter demand effects, strength measurements were taken at the end of the second part. The second part took place within six weeks after the first part in our experimental lab using z-Tree (Fishbacher, 2007). Each participant played the war-of-attrition game against the same opponent only once, in a randomized order. Sessions had between 6 and18 participants.

In our main treatment, the Mutual Assessment Treatment, participants saw a picture of the body silhouette of their opponent before playing a round of the war-of-attrition game. At the beginning of each round, participants looked up the silhouette of their otherwise anonymous ${ }^{6}$ opponent in a booklet of pictures. The Self-Assessment Treatment in Study 2 mirrored the Mutual Assessment Treatment, with the exception that participants did not get information about their opponent.

Every game started with each participant having 225 Experimental Currency Units (ECU) from which 1 ECU got deducted for each second both participants continued the game. By clicking a button, each participant could withdraw from the game at any time with a payoff of [225 -

\footnotetext{
${ }^{5}$ Because of a shoulder injury, we could not obtain all physical measurements from an additional participant. The 13 contests he was involved in had to be dropped from the data.

${ }^{6}$ Anonymity avoids several possible confounds, but may affect the extent to which conflict-related psychological processes are triggered. We discuss this in the concluding section.
} 
duration of contest in seconds] ECU and would leave the other contestant, who would receive a prize of 100 ECU for persisting longest, with a payoff of [100 + 225 - duration of contest in seconds] ECU. In case no one withdrew before 225 seconds elapsed, the prize was split and both contestants received a payoff of 50 ECU. After each game, participants received feedback about the duration of the contest, whether the participant won or lost (i.e., withdrew from) the contest, and their payoffs. After the games, participants completed a questionnaire (see ESM), had their physical measures recorded (Table S1), and received their payment in cash (Study 2) or by bank transfer (Study 3) for one randomly selected war-of-attrition game (1 ECU=.35 Danish kroners $\approx$ 5 US cents). Similar to Sell et al. (2009a), we combined standardized scores for chest and handgrip strength, bicep circumference, and a self-reported measure of physical strength into a composite measure of physical strength (Cronbach’s $\alpha=.81$ in Study 2; $\alpha=.69$ in Study 3).

\section{Results}

To test the hypothesis that conflicts in the Mutual Assessment Treatment are resolved more quickly when the difference in upper-body strength is larger, we employ negative binomial regressions. This empirical model is well suited to handle both the count structure of our data (Hilbe 2011) contest duration is measured in seconds - and the exponentially declining distribution of contest durations predicted by models of the war of attrition (Bishop \& Cannings, 1978; Hammerstein \& Parker, 1982). Likelihood-ratio tests reject the alternative of using poisson regressions (Tables S2 and S3). 
Fig. 2. The effect of differences in strength on conflict duration in the Mutual Assessment Treatment. An increased absolute difference in strength between the contestants decreases the predicted duration of the contest in study 2 (Table S2, model 1) but not in Study 3 (Table S3, model 1) The dashed lines show 95\% confidence intervals based on two-way clustering of standard errors at the contestant level. The white area shows the 5th to 95th percentile range in the data.

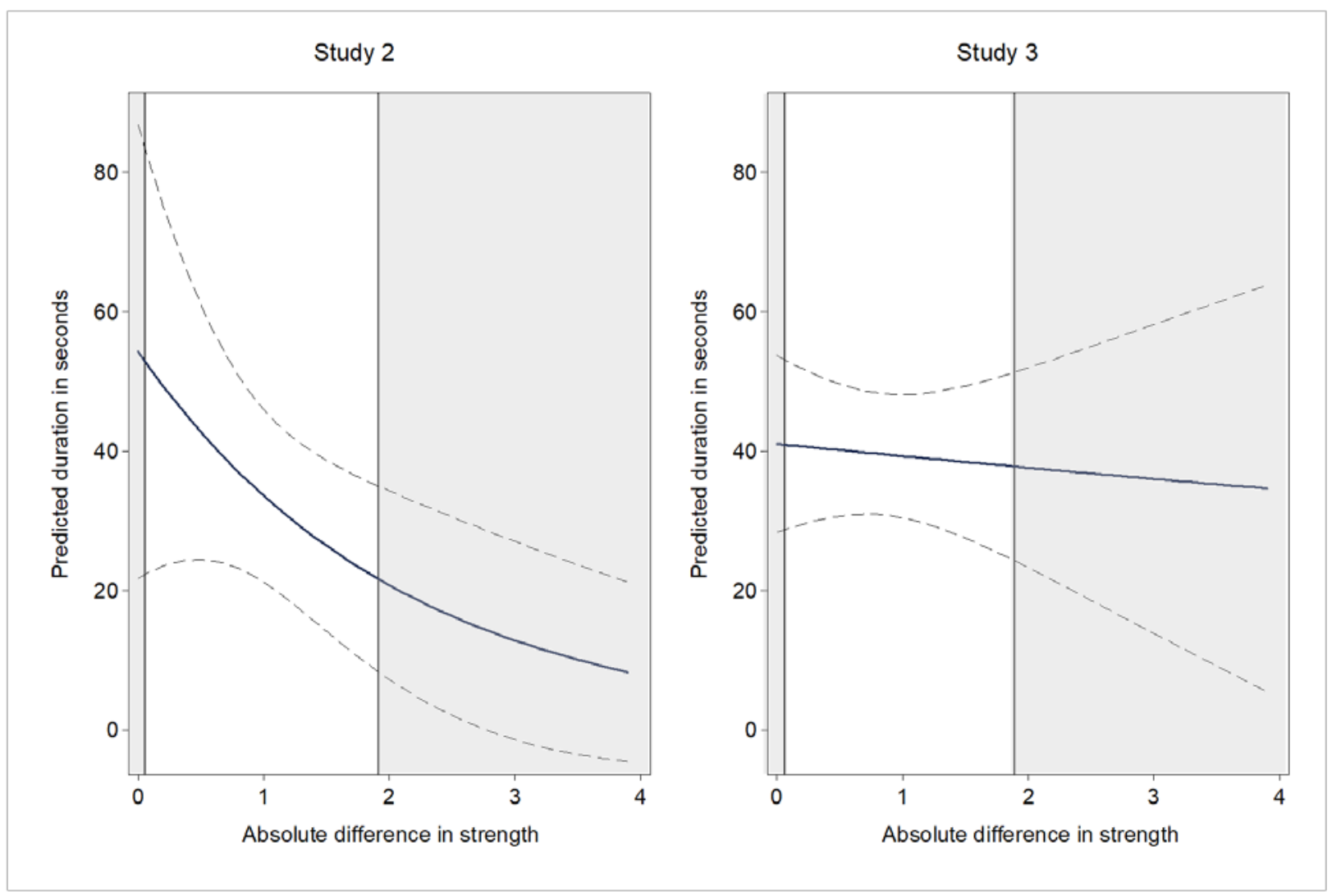

A regression of contest duration on the absolute difference in upper-body strength in the Mutual Assessment Treatment (duration: $M=39.01, S D=61.07$ in Study 2; $M=40.11, S D=57.18$ in Study 3) reveals a marginally significant negative coefficient of relative strength in Study 2 ( $\beta$ $=-.48, p=.06, \mathrm{~N}=205)$, which however fails to replicate in Study $3(\beta=-1.70, \mathrm{p}=.67, \mathrm{~N}=651)$. The coefficients correspond to a standardized marginal effect of -.19 in Study 2 and -.02 in Study 3 at the mean difference in strength (illustrated in the top panel of Figure 2).

According to the second hypothesis, the stronger contestants should be more likely to win the contest and the probability of winning should rise if there are greater asymmetries between contestants. A logistic regression of the binary outcome variable, whether the strongest in the pair won a game that did not end in a draw, on the absolute difference in strength reveals no significant 
main effect. Exploratory data analysis in Study 2 revealed a statistically significant concave relationship - first increasing and then decreasing - of relative strength on the probability of the stronger contestant winning as illustrated in panel a) of Figure 3.

Study 3 does not replicate this finding (joint test of linear and quadratic terms, $\chi^{2}(2, N=191)=6.23$, $p=.04$ in Study 2; $\chi^{2}(2, \mathrm{~N}=611)=4.31, p=.12$ in Study 3). Arguably, the effect of relative strength should be strongest when coordination is achieved instantaneously. For games where one of the contestants immediately withdraws, we find a marginally significant positive coefficient of relative strength in Study $2(\beta=1.56, p=.099, \mathrm{~N}=41)$, which however does not replicate in Study $3(\beta=$ $.10, p=.80, \mathrm{~N}=80$ ). The coefficients correspond in Study 2 (Study 3) to a 10.84 percentage

Fig. 3. Who wins the contests in the Mutual Assessment Treatment.

Relation between absolute difference in strength between the contestants and the predicted probability that the winner is the stronger contestant (a \& b) for all contests that do not end in a draw (based on model 2 in Tables S4 \& S5) and (c \& d) for the contests that ended within the first second (based on model 5 in Tables S4 \& S5). The dashed lines show 95\% confidence intervals based on two-way clustering of standard errors at the contestant level. The white area shows the 5th to 95th percentile range in the data.

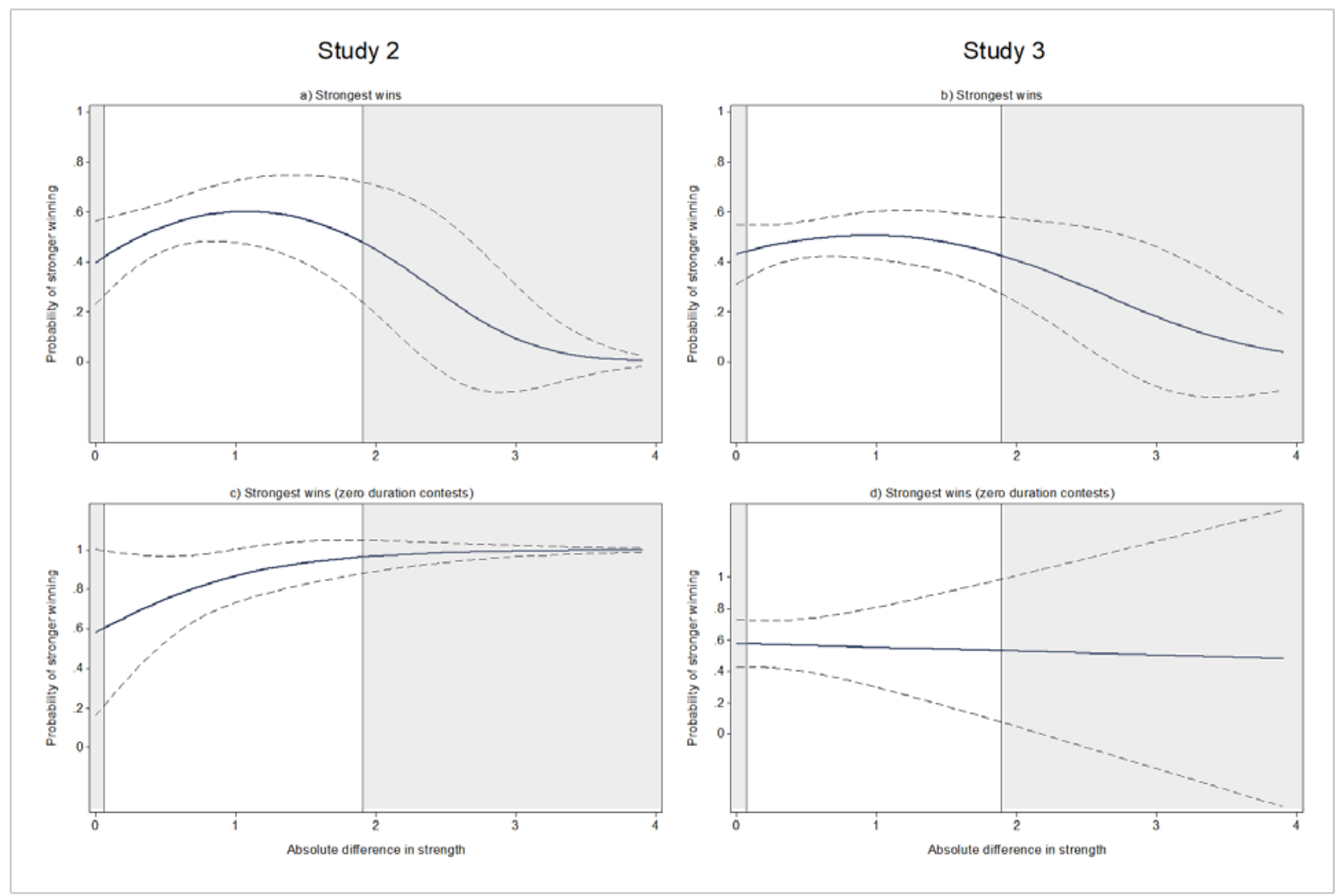


point increase (1.46 percentage point decrease) in the probability of the stronger contestant winning when the difference in strength increases by one standard deviation, as illustrated in panels c and d of Figure 3.

Ex ante, a concern with the above type of analysis was that it might reflect a combination of independent effects that do not rely on relative strength assessment. Specifically, from the literature on animal contests we know that a negative relation between asymmetry in strength and contest duration may also emerge if the endurance of a contestant increases with his own strength and cues about the strength of the rival play no role (Taylor \& Elwood, 2003). We address this issue in two ways.

First, we apply a method developed by Taylor \& Elwood (2003) for studies of animal contests. If contestants mutually assess their relative strength and modulate their decisions accordingly (referred to as the mutual assessment model), contest duration increases (decreases) with the weaker (stronger) rival's strength because this reduces (increases) the asymmetry between contestants (Figure 4a). If contestants' endurance depends only on own strength (referred to as the pure self-assessment model), contest duration increases with both the weaker contestant's strength and, to a lesser degree (because the weaker contestant is likely to give up first), the stronger contestant's strength (Figure 4b). The observed empirical results for Study 2 (Figure 4c) marginally reject the self-assessment hypothesis in favor of the mutual assessment hypothesis (Wald test of both slopes being zero, $\left.\chi^{2}(2, \mathrm{~N}=205)=4.67, \mathrm{p}=.097\right)$. These findings however do not replicate in Study 3 (Figure 4d). While the signs of the coefficients are as expected, the coefficients are not jointly different from zero $\left(\chi^{2}(2, \mathrm{~N}=651)=.24, \mathrm{p}=.886\right)$. 
Fig. 4. Evidence for mutual assessment.

(a) The Mutual Assessment model predicts that contest duration is determined by the difference in strength, which increases (decreases) with the strength of the stronger (weaker) contestant. (b) The Pure Self-Assessment Model predicts that contest duration is determined by a contestant's own strength. The key difference in predictions is the effect the strength of the stronger contestant has. (c \& d) The predicted duration of the contests derived from the negative binomial regressions for the Mutual Assessment Treatment (model 7 in Tables S2 \& S3). The top (bottom) graph holds the strength of the stronger (weaker) contestant fixed at the average observed value. The dashed lines show 95\% confidence intervals based on two-way clustering of standard errors at the contestant level.
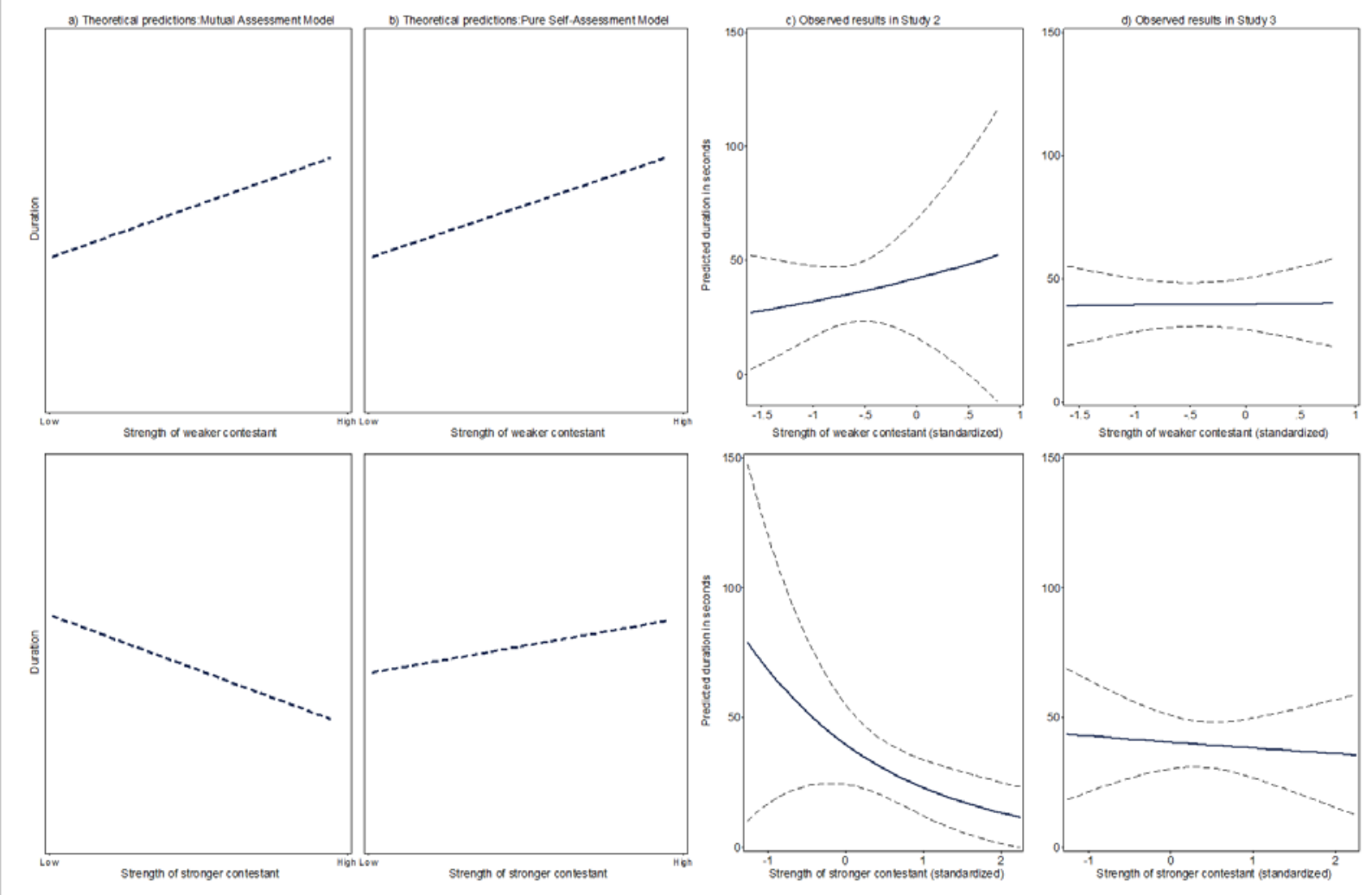

Second, if contest behavior was determined by processes within each participant, data patterns qualitatively similar to those in our main treatment should emerge in the Self-Assessment Treatment, where no information about the strength of the opponent is available. In contrast, if behavior relies on simultaneous information about both the self and the opponent, then relative 
strength should predict outcomes in the Mutual Assessment Treatment but not the Self-Assessment Treatment. Consistent with the latter hypothesis, in Study 2 we replicated our findings for the Mutual Assessment Treatment but (i) the duration of a contest in the Self-Assessment Treatment (duration: $M=27.24, S D=48.86$ ) was neither significantly related to the difference in strength between the contestants nor the strength of the stronger contestant within each pair; (ii) the stronger contestant in a pair was not most likely to win (Table S6).

\section{Study 4: Possible psychological mediators}

A shared intuition that the relatively stronger contestant should prevail could act as a focal point (Schelling 1960) for coordinating on one of the multiple game theoretic equilibria of the war of attrition game - namely on the equilibrium where the weaker contestant withdraws. ${ }^{7}$ Recent evidence, however, showed that physical strength affects the amount of resources that players cede to others also when there is no coordination problem: In the ultimatum game, male first-movers make higher offers to relatively more physically strong male second-movers (Eisenbruch et al., 2016). This suggested that the effect of relative strength on contest outcomes that we observed in Study 2 was not just the result of a mechanism that recognizes a coordination problem and selects a focal point among available cues from the environment; but opened up for the possibility that it was driven by more general psychological processes triggered by perceptions of relative strength differences. A pre-registered ${ }^{8}$ follow-up study (Study 4) was designed to investigate this.

\footnotetext{
${ }^{7}$ Another equilibrium calls for the stronger contestant to withdraw and, in addition, there are so-called mixed strategy equilibria where contestants only withdraw with a certain probability at any given point in time (Bishop \& Cannings, 1978; Hammerstein \& Parker, 1982).

${ }^{8}$ Available at osf.io/ytr5q
} 
In Study 4, we explored four possible mechanisms: First, the most literal interpretation of the AWA-model is that resource allocations depend on the relative ability of each individual to inflict damage on the other. Accordingly, physically stronger men have a stronger sense of entitlement and are more willing to use force to resolve conflicts in their favor. With this mechanism, contestants should perceive relatively stronger rivals as more prone to aggression and defer to them because these are likely to win a violent conflict. ${ }^{9}$

Second, an alternative hypothesis is that the evolutionary pressures captured by the AWAmodel resulted in physically stronger men being endowed with psychological traits of dominance. Because these traits commit them to applying more 'hawkish' strategies, strong men are used to getting their way. With this mechanism, contestants defer to relatively stronger rivals because these are believed to adopt more aggressive strategies in the game, and not because of the threat of physical confrontation.

Third, physical strength is associated with health, productivity, and status (Lukaszewski et al., 2016). Consequently, contestants may defer to relatively stronger rivals because these are seen as valuable friends with whom to build a future cooperative relationship (Eisenbruch et al., 2016).

Finally, physical prowess is stereotypically associated with a lack of intelligence (Sailes, 1993) and, hence, physical strength could be perceived as a cue for a strategy that is excessively aggressive and not informed by an 'intelligent' assessment of the situation. With this mechanism,

\footnotetext{
${ }^{9}$ An anonymous reviewer provided a nice illustration. In the 1977 Star Wars film, Han Solo advises C-3PO not to beat Chewbacca (who is very strong physically) at chess, to avoid getting his arm pulled out of its socket. So even though Chewbacca's strength seems rationally irrelevant to chess, it still advantages him in chess because his opponents fear physical revenge if he should lose.
} 
contestants defer to relatively stronger rivals because it seems risky to stay in the game with an opponent who might be confused about the disadvantage of perseverance.

The first mechanism (perceptions of aggression) is clearly in line with the AWA-model as laid out in the Introduction and the interpretation of the economic game as a conflict situation. The second mechanism (perceptions of dominance) could be seen as being in line with these arguments, while the third (valuable friend) and fourth (lack of intelligence) mechanisms are best viewed as alternative theories.

As reported below, Study 4 found support for the first mechanism. We aimed to replicate the mediation pattern in the replication study (Study 3) and present these findings here as well.

\section{Methods}

Study 4. 375 male participants (age: $\mathrm{M}=30.16$, $\mathrm{SD}=6.41$ ) were recruited through a Qualtrics Panel from the USA and paid 6 US dollars for completing an online survey. Participants were randomly assigned to one of four conditions. For each of the 42 pictures of a body silhouette from the Mutual Assessment Treatment they rated on a 7-point Likert scale whether the person shown is Condition 1: someone who is prone to physical aggression, Condition 2: someone who is used to getting his way, Condition 3: someone who is a valuable friend, Condition 4: someone who is intelligent.

Study 3 implemented the Mutual Assessment Treatment according to the procedures of Study 2, with a modification that allowed us to replicate the mediation analysis of Study 4 . At the beginning of each war of attrition game, when participants looked up the silhouette of their otherwise 
anonymous opponent in a booklet of pictures, they rated whether the person shown is someone who is prone to physical aggression.

To assess how each of these mechanisms contribute to the findings obtained in Study 2, we perform two sets of analyses. First, we examine the simple correlations between the mean ratings of personality features and the actual strength of the person shown in the picture. Only perceived personality features that strongly correlate with actual strength are likely mediators of the effects observed in Study 2.

Second, we combine the mean ratings of personality features from Study 3 with the data from Study 2 and examine potential mediation effects. We construct the mediator variables as follows. For each picture, we compute the mean rating along a personality feature and standardized mean ratings across the 42 pictures. The mediator variable is the absolute difference in standardized ratings for a particular personality feature for the two contestants in a game.

In a linear model, one can measure the degree to which a variable $\mathrm{M}$ mediates the effect of $\mathrm{X}$ on outcome $\mathrm{Y}$ simply by comparing the regression coefficients of $\mathrm{X}$ between a full model with the mediator $\mathrm{M}$ included (direct effect of $\mathrm{X}$ on $\mathrm{Y}$ ) and a reduced model without $\mathrm{M}$ included (total effect of $\mathrm{X}$ on $\mathrm{Y}$ ). Duration models however are non-linear and one cannot directly compare the full and reduced models, because excluding the mediator $\mathrm{M}$ affects the scaling of the coefficient on X. To investigate the extent to which the relationship between differences in physical strength and contest duration is mediated by one of the mechanisms, we use a decomposition method that allows for cross-model comparison of nonlinear models with linear effects (Kohler et al, 2011). The method solves the rescaling issue by including in the reduced model the residuals from an auxiliary regression of $\mathrm{M}$ on $\mathrm{X}$, making it comparable with the full model. 
We cannot offer a similar decomposition of the effect of differences in strength on the probability that the stronger contestant wins because we are not aware of any techniques for mediation analysis in binary dependent variable models with non-linear effects.

\section{Results}

Considering the correlations of mean ratings of personality features with the strength of the person shown in the picture (Table S10), as expected, stronger men in Study 2 were rated to be more prone to aggression $(r=.63, p<.001, N=42)$; and more used to getting their way $(r=.49, p<$ .001). But there was a marginally significant negative correlation with being perceived as a valuable friend $(\mathrm{r}=-.28, \mathrm{p}=.077)$ and no significant correlation with intelligence $(\mathrm{r}=-.25, \mathrm{p}=.11)$. This provides suggestive evidence that the two predicted mechanisms drive the effects of formidability in Study 2 and not the mechanisms proposed by the alternative theories.

Next, we directly investigate the mediation effects. We find a significant mediation effect through proneness to aggression, which explains around $47 \%$ of the coefficient value of relative strength. None of the other mediators are significant (Table S11). Figure 4 compares the direct, unmediated effect of differences in strength on contest duration to the total effect. One sees that the findings from Study 4 do not replicate in our replication study (Study 3). In the latter, we also do not find a significant correlation between strength and being rated as prone to aggression $(r=$ $.02, p=.60, N=651$ ratings (one per game used)). 


\section{Fig. 5. Mediation}

The figure shows the predicted duration of the contests derived from negative binomial regressions for the Mutual Assessment Treatment (Tables S11 and S12). It compares the effect of absolute differences in strength on contest duration without the mediator included (total effect) to the effect net of mediation through differences in proneness to aggression (direct effect).

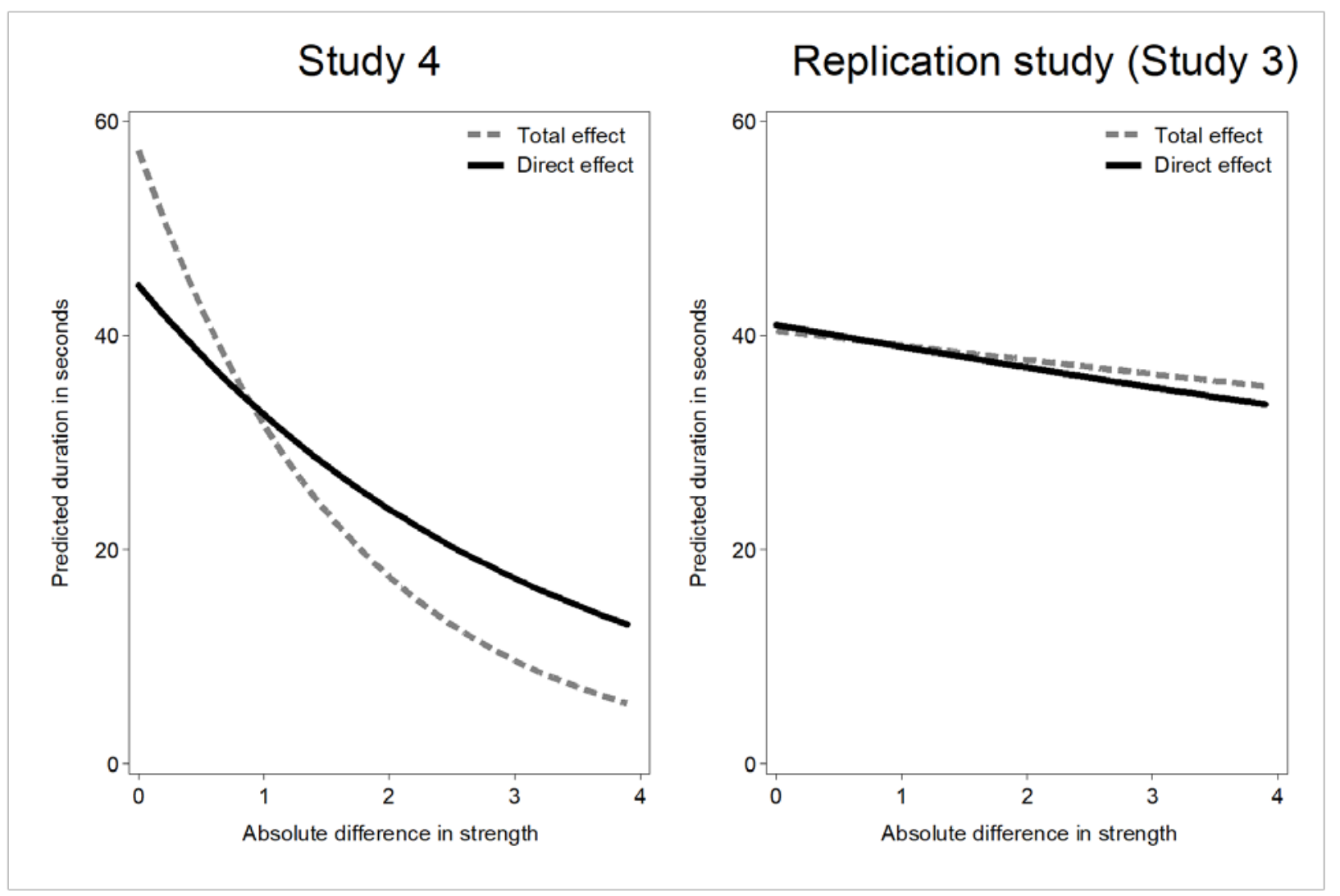

\section{Discussion}

In this manuscript, we have provided the first experimental and behavioral test of whether human males intuitively resolve conflicts by utilizing cues of physical strengths. In spiders, frogs, deer, crickets, lions and many other species, a cognitive architecture has been identified that allows these organisms to quickly resolve conflicts by assessing physical cues to the relative fighting ability of contestants and, on the basis of this assessment, resolve the conflict in favor of the predicted winner without engaging in fights. Specifically, we tested the strong version of whether a similar dynamic obtains in humans: Whether human males spontaneously resolve conflicts on the basis of relative 
physical strength, even in the evolutionarily novel conflict settings where physical strength is irrelevant for the pay-offs. While our initial studies provided support for this strong hypothesis, pre-registered and well-powered follow up analyses failed to provide support. We conclude that the total evidence speaks against the hypothesis that human males utilize cues to strength to resolve conflicts in situations where strength is payoff-irrelevant.

There are a few important caveats. First, conflict can take many different forms. Because a significant part of prior work on humans and upper-body strength is explicitly grounded in the Asymmetric War of Attrition model, the natural starting point for our studies was a design that came as true to the original formulation of this model as possible. Yet, conflicts often follow a win-lose, zero sum game logic. While parties also do compete over a scarce resource in the war of attrition game, coordination on the stronger opponent getting the resource allows both parties to avoid costs from engaging in conflict. Whether the essence of conflict is better captured by a zerosum or a non-zero sum game is debatable (Burton 1990). In any case, one type of conflict setting may trigger different psychological responses than others. In this way, we believe that our findings reveal the boundary conditions of the causal impact of relative differences in upper-body strength. Thus, the findings suggest that relative differences in strength are not utilized in non-physical conflict situations where coordination for mutual benefit is possible. Yet, it is certainly possible that they do apply in zero-sum conflict situations. Studying whether the results apply in zero-sum games is an important avenue for future research. In this regard, we believe that the present set of studies contributes with a fruitful approach that can be efficiently implemented in zero-sum conflict games as well. 
Second, and relatedly, it is important to note that there are multiple strategies and psychological responses that can shape behavior in the war of attrition game. In particular, risk aversion might be important. Risk averse individuals may be motivated to immediately opt out of the war of attrition game as a general strategy, independently of relative differences in strength. Risk-aversion is a relatively stable psychological trait that may be related to individual differences in upper-body strength and, hence, such psychological dynamics could obscure the effects of relative differences in upper-body strength. While we cannot completely rule out that this, or other, psychological dynamics could confound the tested effects of upper-body strength, it is important to note that we did control in the analyses for individual differences in risk aversion and also that Study 2 found the strongest support for an effect of relative differences in upper-body strength in dyads where one contestant immediately left the contest. This speaks against risk averse strategies for immediately opting out of the contest having introduced a bias in the present findings.

Third, to the extent that future studies utilize the approach developed here, they may consider changing individual elements of the approach. In the present studies, individuals were exposed to visual cues about the opponent's strength, but still we preserved anonymity in our experiments. Anonymity has the advantage that subjects credibly face a one-shot interaction with the opponent, whereas if pictures allow subjects to identify each other, subjects could be influenced by the possibility that they will be confronted by other subjects about their actions. While exposure to silhouettes captures some aspects that would inform first-impression judgements, our design misses features of real life conflicts, such as having an identifiable victim (Bohnet and Frey 1999) and the ability to scrutinize the facial expression of the opponent (Schmidt and Cohn 2001, Clark et al 2020). In addition, genuinely one-shot interactions are rare in real life so that the possibility 
of post-interaction revenge may be relevant. Exploring the importance of these features for first impression judgements and conflict resolution is another important avenue for future research.

A final caveat is that the rejection of the strong AWA-hypothesis does not necessarily invalidate the studies described in the Introduction, which originally formulated the strong version of the AWA-hypothesis as applied to humans. They found a relation between individual differences in male upper-body strength and attitudes on mass-political issues - a setting where physical strength is irrelevant. On the one hand, the present findings could imply that these associations are spurious. On the other hand, political attitudes such as militarism and antiegalitarianism could still be causally related to differences in strength with strength-calibrated personality traits such as aggressiveness (see Petersen \& Dawes, 2017) or assertiveness (Lukaszewski, 2013) as mediators. Such strength-calibrated personality might reflect facultative adaptations to an ancestral social environment in which conflicts almost always could escalate into physical confrontation. Future research should aim to cleanly test such causal effects. For now, the present findings however caution against applying to humans the strong version of the AWA model.

Author Contributions. D.N., M.P.B., J.N. and A.K. designed the study. D.N and A.K. conducted the experiments. D.N. and A.K. analyzed the data. D.N., M.P.B., and A.K. interpreted the results and wrote the manuscript. All authors approved the final version of the manuscript for submission. 


\section{References}

Archer, J., \& Thanzami, V. (2007). The relation between physical aggression, size and strength, among a sample of young Indian men. Personality and Individual Differences, 43(3), 627-633.

Arnott, G., \& Elwood, R. W. (2009). Assessment of fighting ability in animal contests. Animal Behaviour, 77(5), 991-1004.

Bishop, D. T., \& Cannings, C. (1978). A generalized war of attrition. Journal of Theoretical Biology, 70(1), 85-124.

Böckerman, P., Johansson, E., Kiiskinen, U., \& Heliövaara, M. (2010). The relationship between physical work and the height premium: Finnish evidence. Economics \& Human Biology, 8(3), 414420.

Bohnet, I., \& Frey, B. S. (1999). Social distance and other-regarding behavior in dictator games: Comment. American Economic Review, 89(1), 335-339.

Burton, J. (1990). Conflict: Human needs theory. Springer.

Case, A., \& Paxson, C. (2008). Stature and Status: Height, Ability, and Labor Market Outcomes. Journal of Political Economy, 116(3).

Chagnon, N.A. (1983). Yanomamö: The Fierce People. Holt, Rinehart \& Winston, New York.

Clark, L., Butler, K., Ritchie, K. L., \& Maréchal, L. (2020). The importance of first impression judgements in interspecies interactions. Scientific Reports, 10(1), 1-10.

Daly, M., \& Wilson, M. (1988). Homicide. Transaction Publishers.

Dechenaux, E., Kovenock, D., \& Sheremeta, R. M. (2015). A survey of experimental research on contests, all-pay auctions and tournaments. Experimental Economics, 18(4), 609-669.

DeScioli, P., \& Wilson, B. J. (2011). The territorial foundations of human property. Evolution and Human Behavior, 32(5), 297-304. 
RUNNING HEAD: Do Physically STRONGER MALEs PreVAIL In NON-Physical Conflicts?

De Waal, F. B. (2000). Primates--a natural heritage of conflict resolution. Science, 289(5479), 586590.

Eisenbruch, A. B., Grillot, R. L., Maestripieri, D., \& Roney, J. R. (2016). Evidence of partner choice heuristics in a one-shot bargaining game. Evolution and Human Behavior, 37, 429-439.

Fischbacher, U. (2007). z-Tree: Zurich toolbox for ready-made economic experiments. Experimental economics, 10(2), 171-178.

Grueter, C. C., Isler, K., \& Dixson, B. J. (2015). Are badges of status adaptive in large complex primate groups? Evolution and Human Behavior, 36(5), 398-406.

Hagen, E. H., \& Hammerstein, P. (2006). Game theory and human evolution: A critique of some recent interpretations of experimental games. Theoretical Population Biology, 69(3), 339-348.

Hardy, I. C., \& Briffa, M. (Eds.). (2013). Animal contests. Cambridge University Press.

Hammerstein, P., \& Parker, G. A. (1982). The asymmetric war of attrition. Journal of Theoretical Biology, 96(4), 647-682.

Hilbe, J.M. (2011). Negative Binomial Regression. $2^{\text {nd }}$ edition, Cambridge, U.K.: Cambridge University Press.

Hörisch, H., \& Kirchkamp, O. (2010). Less fighting than expected. Public Choice, 144(1-2), 347367.

Kohler, U., Karlson, K.B., \& Holm, A. (2011). Comparing Coefficients of nested nonlinear probability models. The Stata Journal, 11(3), 420-438.

Li, N. P., van Vugt, M., \& Colarelli, S. M. (2018). The evolutionary mismatch hypothesis: Implications for psychological science. Current Directions in Psychological Science, 27(1), 3844. 
RUNNING HEAD: Do Physically STRONGER MALEs PreVAIL In NON-Physical Conflicts?

Lukaszewski, A. W., Simmons, Z. L., Anderson, C., \& Roney, J. R. (2016). The role of physical formidability in human social status allocation. Journal of Personality and Social Psychology, 110(3), 385.

Lukaszewski, A. W. (2013). Testing an adaptationist theory of trait covariation: Relative bargaining power as a common calibrator of an interpersonal syndrome. European Journal of Personality, 27(4), 328-345.

Lundborg, P., Nystedt, P., \& Rooth, D. O. (2014). Height and earnings: The role of cognitive and noncognitive skills. Journal of Human Resources, 49(1), 141-166.

Maynard Smith, J. \& Parker, G.A. (1976). The logic of asymmetric contests. Animal Behaviour 24, 159-4175.

Parker, G. A. (1974). Assessment strategy and the evolution of fighting behaviour. Journal of theoretical Biology, 47(1), 223-243.

Persico, N., Postlewaite, A., \& Silverman, D. (2004). The Effect of Adolescent Experience on Labor Market Outcomes: The Case of Height. Journal of Political Economy, 112(5), 1019-1053.

Petersen, M. B., \& Laustsen, L. (2019). Upper-Body Strength and Political Egalitarianism: Twelve Conceptual Replications. Political Psychology, 40(2), 375-394.

Petersen, M. B., \& Dawes, C. T. (2017). Assessing causal pathways between physical formidability and aggression in human males. Personality and individual differences, 113, 161166.

Pietraszewski, D., \& Shaw, A. (2015). Not by Strength Alone. Human Nature,26(1), 44-72.

Price, M. E., Dunn, J., Hopkins, S., \& Kang, J. (2012). Anthropometric correlates of human anger. Evolution and Human Behavior, 33(3), 174-181.

Price, M. E., Kang, J., Dunn, J., \& Hopkins, S. (2011). Muscularity and attractiveness as predictors of human egalitarianism. Personality and Individual Differences, 50(5), 636-640. 


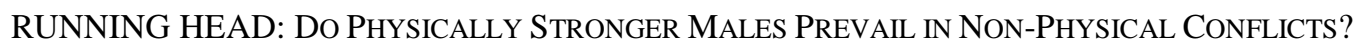

Puts, D. A. (2010). Beauty and the beast: Mechanisms of sexual selection in humans. Evolution and Human Behavior, 31(3), 157-175.

Sailes, G. A. (1993). An investigation of campus stereotypes: The myth of Black athletic superiority and the dumb jock stereotype. Sociology of Sport Journal, 10(1), 88-97.

Schelling, T.C. (1960). The Strategy of Conflict. Harvard University Press.

Schmidt, K. L., \& Cohn, J. F. (2001). Human facial expressions as adaptations: Evolutionary questions in facial expression research. American Journal of Physical Anthropology, 116(S33), 324.

Sell, A., Bryant, G. A., Cosmides, L., Tooby, J., Sznycer, D., Von Rueden, C. \& Gurven, M. (2010). Adaptations in humans for assessing physical strength from the voice. Proceedings of the Royal Society of London B: Biological Sciences, 277(1699), 3509-3518.

Sell, A., Hone, L. S., \& Pound, N. (2012). The importance of physical strength to human males. Human Nature, 23(1), 30-44.

Sell, A., Tooby, J., \& Cosmides, L. (2009a). Formidability and the logic of human anger. Proceedings of the National Academy of Sciences, 106(35), 15073-15078.

Sell, A., Cosmides, L., Tooby, J., Sznycer, D., von Rueden, C., \& Gurven, M. (2009b). Human adaptations for the visual assessment of strength and fighting ability from the body and face. Proceedings of the Royal Society of London B: Biological Sciences, 276(1656), 575-584.

Sell, A., Sznycer, D., Cosmides, L., Tooby, J., Krauss, A., Nisu, S., \& Petersen, M. B. (2017). Physically strong men are more militant: A test across four countries. Evolution and Human Behavior, 38(3), 334-340.

Taylor, P. W., \& Elwood, R. W. (2003). The mismeasure of animal contests. Animal Behaviour, 65(6), 1195-1202. 
Thomsen, L., Frankenhuis, W. E., Ingold-Smith, M., \& Carey, S. (2011). Big and mighty: Preverbal infants mentally represent social dominance. Science,331(6016), 477-480.

Thomsen, L. (2020). The Developmental Origins of Social Hierarchy: How infants and young children mentally represent and respond to power and status. Current Opinion in Psychology, 33, 201-208 


\title{
ELECTRONIC SUPPLEMENTARY MATERIALS:
}

\section{Do Physically Stronger Males Prevail in Non-Physical Conflicts?}

\author{
Dan Nguyen \\ Department of Economics and Business Economics, Aarhus University \\ Michael Bang Petersen \\ Department of Political Science, Aarhus University \\ Julia Nafziger \\ Department of Economics and Business Economics, Aarhus University \\ Alexander K. Koch \\ Department of Economics and Business Economics, Aarhus University
}

\begin{abstract}
Author Note
Address correspondence to Alexander Koch, Department of Economics and Business Economics, Aarhus University, Fuglesangs Allé 4, 8210 Aarhus V, Denmark. E-mail: akoch@econ.au.dk
\end{abstract}




\section{Details on Study 1}

\section{Methods}

Participants. The study consisted of two stages. The first stage entailed gathering material for the second stage, which was an online, survey-based experiment. Participants in the first stage are referred to as targets, while participants in the second stage are referred to as raters. For the first stage, 50 male students were recruited on the university campus. For their participation, they were given a coffee-voucher (worth 7 Danish kroners $(\mathrm{DKK}) \approx 1$ USD) and they entered a competition to win one of three gift cards worth 200 DKK. The chance of winning depended on how they performed on the strength tests (explained below).

We took the following measures: their height $(M=182.86 \mathrm{~cm}, \mathrm{SD}=6.44)$, their weight $(\mathrm{M}=81.08 \mathrm{~kg}, \mathrm{SD}=6.44)$, their chest strength $($ mean $=54.12 \mathrm{~kg} / \mathrm{F}, \mathrm{sd}=14.46)$, their handgrip strength $(\mathrm{M}=55.66 \mathrm{~kg} / \mathrm{F}, \mathrm{SD}=8.83)$, the circumference of their flexed biceps $(\mathrm{M}=34.95 \mathrm{~cm}, \mathrm{SD}=2.50)$, and a selfreported strength measure on a scale of 0 to $100^{1}(\mathrm{M}=57.40, \mathrm{SD}=20.53)$. By averaging the standardized chest and handgrip strength, biceps circumference, and self-reported strength we obtained a composite measure, strength, for each subject (Cronbach's $\alpha=.77$ ) to be compared with the ratings in the second stage.

For the second stage, 400 raters were recruited through a Qualtrics Panel from the USA with men aged between 15 and 40 years. Each rater was paid 5 USD for his participation, given that he completed the survey. We conducted four online surveys using the Qualtrics survey software, where the raters

\footnotetext{
${ }^{1}$ The precise question asked was "How physically strong are you? Out of 100 randomly picked men of your age, please state how many you would on average think are less strong than you. If you consider yourself to be stronger than 40 out of 100 men of your age, indicate so by stating $40 . "$
} 
assessed edited pictures from stage 1. By targeting men in the USA, we ensured that raters would not know any of the persons in the photographs from stage 1 that were taken in Denmark.

Design. We now describe the detailed experimental design and procedures of study 1.

Stage 1. Participants went through the following nine steps: 1) Participants showed up at a front desk, placed outside of a closed area made up by moveable walls. They were informed about the purpose and procedure of the study by an experimenter and signed a consent form. 2) One by one, participants entered the closed area. Here they changed into a pair of shorts (two sizes were available and no participants had any problems fitting into one of them). 3) Full body photographs were taken (Fig. S2). The camera was placed on a tripod to ensure stability during the photo session. Each participant was asked to stand at a particular mark on the floor (marked with an X) against a white wall. This ensured that all the pictures had the same sizes. The participants were instructed to keep a neutral facial expression and let their arms hang along their body in a relaxed manner. On the wall, a line was set at one meter height to provide raters in the second part of the study, who assessed the full-body pictures of the targets, with an indication of relative size. 4) We measured the chest strength (Chest). The participants held a dynamometer with inversely set hand grips. Then with both hands they pushed the grips together (Fig. S1a). Two attempts were given and the best result was recorded. They were encouraged to provide maximum effort and knew that better performance would increase their chances of winning one of the gift cards. This applies to step 6 as well. 5) Height (in centimeters) and weight (in kilograms) were measured. 6) Grip strength (Handgrip) was recorded using the participant's dominant arm (Fig. S1b). The participant was asked to hold his elbow at the side of his body and point the arm downward to achieve maximum tension. He then squeezed as hard as he could. Two trials were given and the best result was recorded. 7) A measurement tape was put around the biceps of the participant and he was 
asked to flex it. The circumference of the flexed biceps (in centimeters) was then measured at its widest point. 8) The participant changed back into his own clothes. Then, he filled out a short questionnaire. 9) Once the questionnaire was filled out, the participant exchanged his questionnaire for a coffee voucher at the desk.

Stage 2. To prepare the ratings of the pictures, one picture of each participant in stage 1 (target) was chosen, gray-scaled to reduce effects of skin color, and edited into four different versions using Adobe Photoshop CS5: a full-body picture (with covered face), a body silhouette, a face picture, and a silhouette of the face (Fig. S2). From the full body pictures of the 50 targets in the first stage, we hence obtained 200 unique stimuli. The stimuli were divided into four different surveys. Pictures were randomly split into two groups, A and B, for which the mean physical strength level of the persons in the pictures was not significantly different (two-tailed t-test, $\mathrm{p}=.35$ ), that is both sets exposed raters to pictures of participants with comparable levels of physical strength.

Four surveys, which each contained 50 pictures, were constructed as follows. Two surveys contained 25 pictures of full bodies of one group (A or B) and 25 pictures of body silhouettes of the other group, so that no target would be rated twice by the same person. The other two surveys contained 25 pictures of faces of one group (A or B) and 25 pictures of face silhouettes of the other group. The surveys varied the order of presentation of the two blocks. Pictures within each block were randomized to overcome potential order effects.

Each rater participated in only one of the surveys. He rated pictures separately on physical strength and physical attractiveness, one picture at a time. Each dimension was scored on a 7-point Likert scale $(1=$ Very weak/homely and $7=$ Very strong/handsome $)$. It was not possible to return to a rated picture. Just before rating each set, raters were shown a picture reel of the 25 pictures they were about to 
rate, one picture per second. With 100 raters in each survey, 100 ratings observations were obtained per picture.

\section{Results}

Averaging the ratings of a particular silhouette across the raters, we find that strangers' average rating of strength from body silhouettes of other men strongly correlated with the actual physical strength of those shown $(\mathrm{r}=.55, \mathrm{p}<.001, \mathrm{~N}=50)$. An OLS regression model with the composite measure of actual strength as the dependent variable and the rating (standardized) as the independent variable revealed a significant average individual accuracy of $\beta=.17(\mathrm{p}<.001, \mathrm{~N}=5,000)$. We applied two-way cluster robust standard errors (Cameron, Gelbach \& Miller 2011) at the rater level (200 clusters) and target level (50 clusters) to account for the repeated interactions (rating multiple pictures). ${ }^{2}$

\section{Details on Study 2}

\section{Methods}

Participants were recruited through advertising on campus or the subject pool of behavioral laboratory facilities at the university. The study consisted of two parts. In the first part, participants had their pictures taken using the same procedure as in Study 1. The photographs of the participants were edited to only reveal the body silhouette. The second part took place in an experimental lab within six weeks after the first part. Participants were contacted by email and reminded to show up on time. All did so. Upon arrival, the participants registered at the front-desk and received a closed envelope containing their player ID and they were assigned to isolated cubicles, based on a prepared random allocation. Each participant received

\footnotetext{
${ }^{2}$ The estimation used the vce2way Stata module by Yoo (2017).
} 
as an ID a randomly drawn 6-digits number. Participants needed to enter this number into a computer at the start of the session, to link each participant to his picture.

Each cubicle contained a computer, a set of instructions and, in the Mutual Assessment Treatment additionally a booklet containing pictures with body silhouettes, printed on thick, high-gloss paper (+120 $\mathrm{g} / \mathrm{m}^{2}$ ). Each body silhouette had its own page (A4-size), prepared according to the procedures from Study 1. As a further safeguard to ensure anonymity of the participants, the face part of the silhouette was replaced by a black circle to avoid the possibility of identification through for example hairstyle. In the upper-right corner of each page, a picture number (different from the participant ID) was stated so that participants could look up their opponents later in the session. Throughout the entire session, sound files with random sequences of mouse-clicking were played through headphones at the non-used computers, adjusted in volume so that the room was filled with the sound of random mouse-clicking that could not be attributed to any particular location in the lab. This was to avoid behavioral spill-overs that could result if participants notice other participants' decisions to click a button on the computer.

At the start of a session, participants were asked to carefully read the instructions ${ }^{3}$ and to answer several questions to check that they had understood the game. Once a participant had completed reading and had answered the questions, he would raise a hand and an experimenter would check the answers and privately follow up on any misunderstandings. After all the participants were finished, the experimenter announced that the experiment was about to begin. Participants were asked to raise their hands if they had any further questions at that stage or later during the experiment. Then the participants were instructed to open the envelope with their participant ID's and were given an entry-code to start the experiment on the computer.

\footnotetext{
${ }^{3}$ Instructions are available from the authors upon request.
} 
In the Mutual Assessment Treatment, before playing a round of the war-of-attrition game, participants were given a picture number so they could look-up the body silhouette of their otherwise anonymous opponent in the booklet of pictures. The Self-Assessment Treatment mirrored the design of the Mutual Assessment Treatment, with the exception that there were no booklets with pictures and participants did not get to see pictures of the body silhouette of their opponent.

In both treatments, every game started with each participant having 225 Experimental Currency Units (ECU) from which 1 ECU got deducted for each second both participants continued the game. By clicking a button, each participant could withdraw from the game at any time with a payoff of [225 duration of contest in seconds] ECU and would leave the other contestant, who would receive a prize of 100 ECU for persisting longest, with a payoff of $[100+225-$ duration of contest in seconds $]$ ECU. In case no one withdrew before the 225 seconds elapsed, the prize was split and both contestants received a payoff of 50 ECU. Before the start of a game, players had to click an "OK"-button when ready. When all players had done so, the game screen appeared and a 10-seconds countdown started. After the countdown, the "STOP"-button would turn from grey to red to indicate that the round had begun. This feature allowed participants to click the button exactly at the start of the game if they so wished. After each game, a screen showed the duration of the contests, whether they had won or lost (i.e., withdrew from) the contest, and their payoffs.

At the end of the experiment, participants completed a brief questionnaire on basic background data and on their risk tolerance using the validated survey measure of Dohmen et al. (2011): "How do you see yourself: Are you generally a person who is fully prepared to take risks or do you try to avoid taking risks? Please tick a box on the scale, where the value 0 means: 'unwilling to take risks' and the value 10 means: 'fully prepared to take risks'. Then participants went to an adjacent room in order to record physical measures using the same procedures as in Study 1. They then received their payment in 
cash for one randomly selected war-of-attrition game ( 1 ECU=.35 Danish kroners $\approx 5$ US cents). This "pay one round" approach helps us avoid hedging considerations and wealth effects on behavior (Charness et al. 2016). In addition, they received a fixed compensation of 80 Danish kroners.

\section{Results}

See Section below that provides details regarding the results from Studies 2 and 3.

\section{Details on Study 3}

\section{Methods}

The pre-registered ${ }^{4}$ study was advertised as a two-part study to the subject pool of the Cognition and Behavior Lab at Aarhus University. 103 subjects participated ${ }^{5}$. Participants first got a full-body photograph taken and then showed up on a different date to a session in a computer lab. They received a fixed compensation of 120 Danish kroners for completing the two-part study and an additional performance-based payment for one randomly selected war-of-attrition game according to the exchange rate from Study 2 (1 ECU=.35 Danish kroners).

The study followed the procedures of the Mutual Assessment Treatment in Study 2, with one exception. At the beginning of each war of attrition game, when participants looked up the silhouette of their otherwise anonymous opponent in a booklet of pictures, they rated whether the person shown is someone who is prone to physical aggression. Specifically, they answered the following question from Study 4: "Please look at the person in the picture. How likely do you think it is that the pictured person

\footnotetext{
${ }^{4}$ Available here: osf.io/emfhx

${ }^{5}$ Because of a shoulder injury, we could not obtain all physical measurements from an additional participant. The 13 contests he was involved in had to be dropped from the data.
} 
is someone who is prone to physical aggression?" Answers were on a 7-point Likert scale (Extremely likely (1), Moderately likely (2), Slightly likely (3), Neither likely nor unlikely (4), Slightly unlikely (5), Moderately unlikely (6), Extremely unlikely (7)). We capped the number of contests that a subject participated in at $\min \{13, \mathrm{~N}-1\}$ contests to keep the total study length comparable to Study 2, where $\mathrm{N} \leq 12$.

To determine the sample size for Study 3, we conducted a power analysis based on the results from Study 2. The main effect for the duration of contests in the Mutual Assessment Treatment in Study 2 had a coefficient of -.48 (Table S2, model 1). We thus operated with a minimum detectable coefficient size of -.4 and a power of at least .8. Fig. S5 shows the power as a function of sample size for a significance level of .05. Based on these power calculations, we aimed to collect data on 350-400 contests in Study 3, which required around 90 subjects. We thus determined that we would collect data until we have 100 participants who completed the two-part study, or until 28th of February 2019, whichever condition was first met.

Power analysis. Using monte carlo simulations, we simulated data for 1,000 experiments for each of the following 66 scenarios: coefficient size $\{-.3,-.4,-.5\}$ x number of subjects $\{50,60,70, \ldots, 150\} \times$ \{low noise, high noise . For each scenario, we ran the model 1 from Table S2 and recorded the fraction of the 1,000 experiments for which the coefficient on the absolute difference in strength was insignificant at the .05 level (rejection frequency). Fig. S5 plots the power, given by 1-(rejection frequency), for the different scenarios.

Specifically, we generated negative binomially distributed random variables derived as a gamma mixture of poisson random variables, according to the following data generating process:

$$
E\left[\text { contest duration }{ }_{i j} \mid x_{i j}, \mu_{i j}\right]=\exp \left\{3+\beta x_{i j}+\omega_{i}+\omega_{j}\right\} \cdot \mu_{i j},
$$


where

- $\quad x_{i j}$ is the absolute difference in strength for contestants $i$ and $j$, that is assumed to have a folded normal distribution: $x_{i j}=\left|s_{i}-s_{j}\right|$ with $s_{i}, s_{j}$ iid $\sim N(0,1)$;

- $\omega_{i}, \omega_{j}$ are independently distributed noise terms specific to contestants $i$ and $j$, respectively, with $\omega_{i}, \omega_{j}$ iid $\sim N\left[0, \sigma^{2}\right]$, we consider both a low and a high noise scenario: $\sigma^{2} \in\left\{\frac{1}{2}, \frac{3}{4}\right\}$;

- $\varepsilon_{i j} \sim \Gamma(1 / \alpha, \alpha)$ is a random unobserved heterogeneity term specific to the contest between contestants $i$ and $j$ that is independent of $x_{i j}$, where the parameter $\alpha=2.5$ matches range found in Table S2.

Figs. S6 and S7 show that the assumptions for the data generating process for |difference in strength| and contest duration are plausible when compared with data from Study 2. We generated poisson random variables around $E\left[\right.$ contest duration $\left.{ }_{i j} \mid x_{i j}, \mu_{i j}\right]$ to fill hypothetical sessions of $\mathrm{N}=10$ participants. This yielded data on $\mathrm{N}(\mathrm{N}-1) / 2=45$ contests per session, based on the stranger matching protocol according to which each subject is in a contest exactly once against each of the other subjects. Then we ran the negative binomial regression model from Table S2 (model 1) with two-way clustering of standard errors at the contestant level, and repeated the sampling 1,000 times.

\section{Results from Studies 2 and 3}

The unit of analysis is a contest between two subjects. All estimated models include period fixed effects and apply two-way cluster robust standard errors (Cameron, Gelbach \& Miller 2011), at the level of 
individual contestants to account for the repeated interactions. ${ }^{6}$ In a session with $\mathrm{N}$ subjects, each subject plays $\mathrm{N}-1$ periods so that the stranger matching procedure generates data on $\mathrm{N}(\mathrm{N}-1) / 2$ contests.

Session sizes. For the Self-Assessment Treatment in Study 2 (N=24), sessions had 6, 8, and 10 subjects, respectively, yielding 106 contests. For the Mutual Assessment Treatment in Study 2 (N=42), sessions had 8, 10, and 12 (two sessions) subjects, respectively, yielding 205 contests. For the Mutual Assessment Treatment in Study 3 (N=103), sessions had 12, 137, 14 (two sessions), 16 (two sessions), and 18 subjects, respectively, yielding 651 contests.

Standardized marginal effect. The standardized marginal effect of -.19 in Study 2 (-.02 in Study 3) for the negative binomial regression of contest duration in the Mutual Assessment Treatment on |difference in strength| is computed by predicting the average marginal effect of |difference in strength| from Table S2 (S3), model 1, dividing it by the standard deviation of contest duration $\mathrm{SD}=61.14$ (57.18), and multiplying it by the standard deviation of |difference in strength| SD=.65 (.59). Fig. S3 (S4), shows the distribution of standardized marginal effects in panel a.

Marginal effects for the probability of the stronger contestant winning. In a similar fashion, we compute a discrete marginal effect that gives the predicted change in the probability of the stronger contestant winning when the difference in strength increases by one standard deviation. For the full sample excluding contests ending in a draw, $\mathrm{N}=191$ in Study 2 ( $\mathrm{N}=611$ in Study 3), the average discrete marginal effect is $-1.51(-.02)$ percentage points. For the contests that were resolved immediately $\mathrm{N}=41$ in Study 2 ( $\mathrm{N}=88$ in Study 3), the average discrete marginal effect is $10.84(-1.46)$ percentage points. Fig. S3 (S4), shows the distribution of these discrete marginal effects in panels b and c.

\footnotetext{
${ }^{6}$ The estimation used the vce2 way Stata module by Yoo (2017).

${ }^{7}$ Because of a shoulder injury, we could not obtain all physical measurements from an additional participant. The 13 contests he was involved in had to be dropped from the data.
} 
Further analysis. According to our hypothesis, contestants should primarily coordinate on upper-body strength because relative upper-body strength for humans is the most important determinant of who would prevail in a physical contest (Sell et al., 2009a). Nevertheless, the pictures of body silhouettes used in the Mutual Assessment Treatment conveyed additional cues to height and body mass index (BMI) that potentially could have been used for coordination.

In line with the prediction of Taylor \& Elwood (2003) for the mutual assessment model (Fig. 3a), we cannot reject that the coefficients on the stronger and weaker contestants' strength have the same absolute value $\left(\right.$ Study 2: $\chi^{2}(1, \mathrm{~N}=205)=.40, \mathrm{p}=.53$; Table $\mathrm{S} 2$, model 7; Study $3: \chi^{2}(1, \mathrm{~N}=651)=.09, \mathrm{p}=.77$; Table S3, model 7).

To test whether relative height or BMI functioned as (additional) coordination devices in the Mutual Assessment Treatment, we include relative height and BMI in the regressions for contest duration. For the likelihood to win a contest, we additionally run regressions on the outcomes whether the tallest (leanest) of the two contestants wins the contest and find no significant effects for either height or BMI (Tables S7 and S8). For contest duration, we find in Study 2 a significant effect of relative height in the direction predicted by the AWA-model: larger differences in height decrease contest durations (Table S2, model 2), but this does not replicate in Study 3 (Table S3, model 2). We do not find a significant effect of relative BMI (Tables S2 and S3, model 4).

Finally, risk preferences might affect competitive behavior (Borghans et al., 2006), and stronger people are often thought to be more willing to take risks (Ball et al., 2010). While our measure of risk tolerance does relate to contest duration in Studies 2 and 4 as one would expect (Tables S2 and S3), we find no correlation between strength and risk tolerance $(r=.01, p=.96, N=66$ for MAT and SAT combined in Study 2; $r=.16, p=.101, N=103$ in Study 3). This is in line with previous findings (Ball 
et al., 2010) and suggests that if there are any strength effects on contest outcomes, these are unmediated by individual differences in risk-taking.

\section{Details on Study 4}

\section{Methods}

In this pre-registered study ${ }^{8}, 375$ male participants were recruited through a Qualtrics Panel from the USA with men aged between 15 and 40 years. Participants were randomly assigned to one of four conditions. In each condition, participants evaluated the set of 42 body silhouettes from the Mutual Assessment Treatment of Study 2 along the personality feature associated with that condition. Before starting to rate the pictures, participants were told that all pictures show men and saw a slide-show showing each of the pictures for 1 second. Participants then rated each picture on the personality feature associated with the condition by answering the following question "Please look at the person in the picture. How likely do you think it is that the pictured person is someone who is <personality feature $>$ " on a 7-point Likert scale (Extremely likely (1), Moderately likely (2), Slightly likely (3), Neither likely nor unlikely (4), Slightly unlikely (5), Moderately unlikely (6), Extremely unlikely (7)). The respective <personality feature> in the four conditions was:

- Condition 1: someone who is prone to physical aggression

- Condition 2: someone who is used to getting his way

- Condition 3: someone who is a valuable friend

- Condition 4: someone who is intelligent

\footnotetext{
${ }^{8}$ Available here: osf.io/ytr5q
} 
The order of pictures was randomized for each participant. For the analysis, ratings were reverse coded such that a higher number indicates that the personality feature is more likely to fit the person in the picture.

\section{Results}

In a linear model, one can measure the degree to which a variable $M$ mediates the effect of $X$ on outcome $Y$ simply by comparing the regression coefficients of $X$ between a full model with the mediator $M$ included (direct effect of $X$ on $\mathrm{Y}$ ) and a reduced model without $M$ included (total effect of $X$ on $Y$ ). We use a decomposition method that allows for cross-model comparison of nonlinear models with linear effects (Kohler et al, 2011). The method solves the issue that coefficients are not comparable across nonlinear models by including in the reduced model the residuals from an auxiliary regression of $M$ on $X$, making it comparable with the full model.

We report bootstrapped standard errors of the direct and indirect effects (1000 replications). Clustering is accounted for using a block bootstrap stratified according to sessions. For each session, participants are drawn with replacement, yielding $\mathrm{N}$ histories of contests for a session of size $\mathrm{N}$. Unlike the original sample, where the $N$ participants interact with each other exactly once, this interim bootstrap sample is not symmetric. To obtain a sample with $\mathrm{N}(\mathrm{N}-1) / 2$ contests, we randomly drop half of the contests from the interim bootstrap sample, stratified by period. The final bootstrap sample has the same number of contests in each period as the original sample. The method extends to multiple mediators by including in the full model a vector of $J$ mediators $\underline{M=\left(M_{1}, \ldots, M_{J}\right)}$ and in the reduced model a vector of $J$ residuals obtained from running for each mediator $j=1 \ldots, J$ an auxiliary regression of $M_{j}$ on $X$. This allows 
us to estimate the relative contribution of all four potential mediators to the overall mediation. All models include period fixed effects. 


\section{Figures}

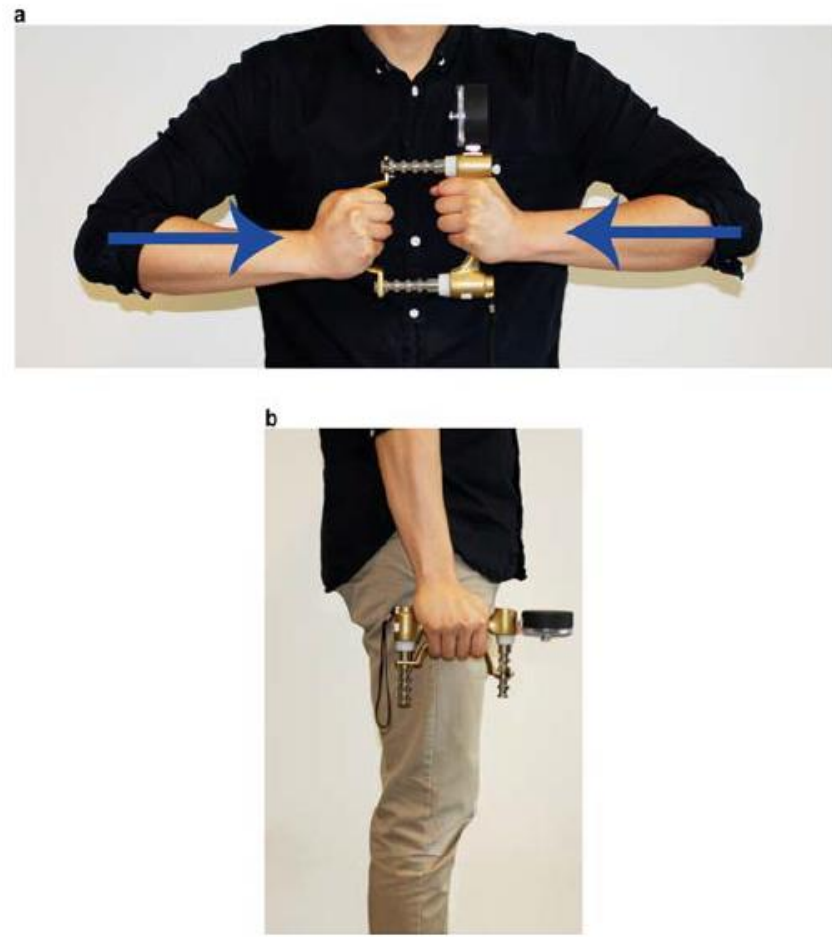

Fig. S1 Illustration of dynamometer measures. a, Assessment of chest strength b, Assessment of grip strength. 


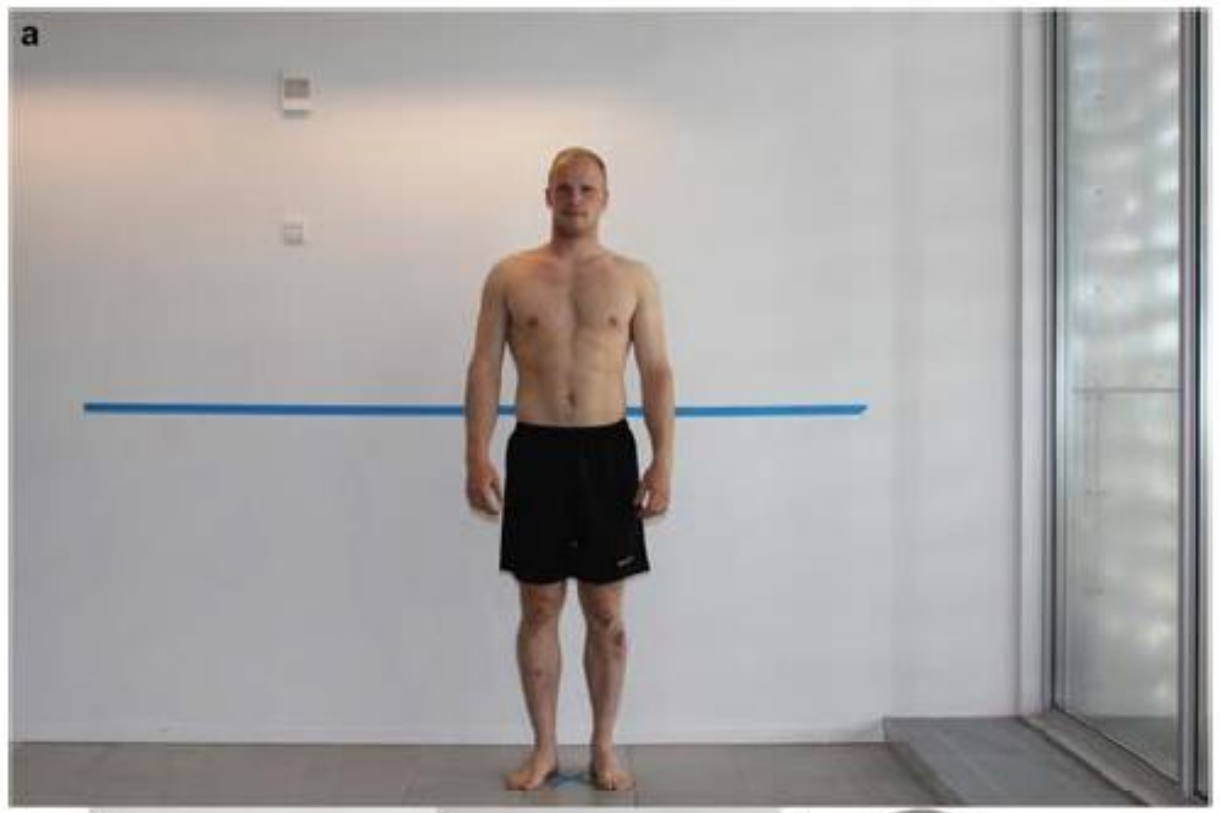

b

C

d

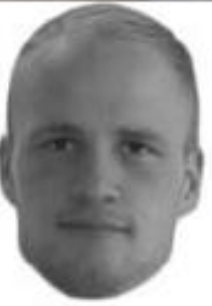

e

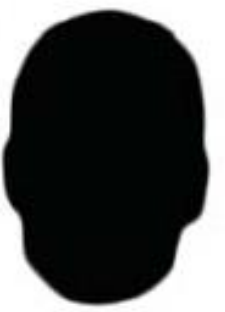

Fig. S2 Examples of the stimuli in Study 1. (a) Original photograph. A horizontal line placed at 1 meter's distance from the floor level provided an indication of relative height. (b) Full body: A picture of the full body in a neutral stance, with the head turned into a silhouette. (c) Body silhouette: A picture of the silhouette of the full body in a neutral stance. Some blurring and rounding was used to smooth out edges on the silhouette. (d) Face: Faces were cropped out from the full body picture and adjusted to a neutral background. Necks were not shown on the pictures. For some faces, the particular light settings of the room made it difficult to distinguish the chin from the neck, complicating separation. As in (Sell et al., 2009b: p. 577) head-sizes were standardized to fill a standard box of 400 pixels in height. (e) Face silhouette: A silhouette of the face, where again edges were smoothed out. 
a) Contest duration

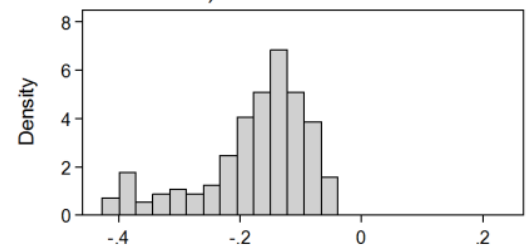

Standardized marginal effect on contest duration

b) Strongest wins

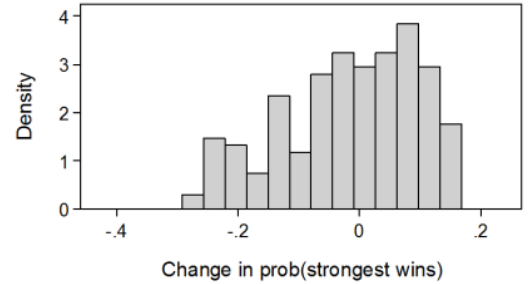

c) Strongest wins (zero duration contests)

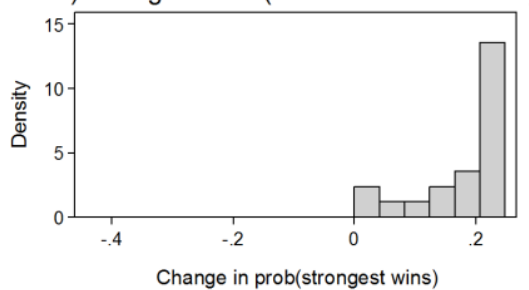

Fig. S3 Study 2: Distribution of the marginal effects of a one standard deviation change in the difference in strength on contest duration and the probability that the strongest contestants wins. The histograms are based on marginal effects computed from (a) Table S2, model 1, (b) Table S4, model 2, and (c) Table S4, model 5.

a) Contest duration

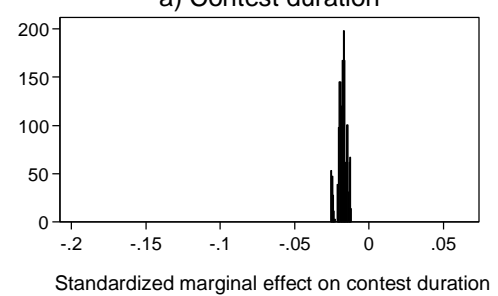

b) Strongest wins

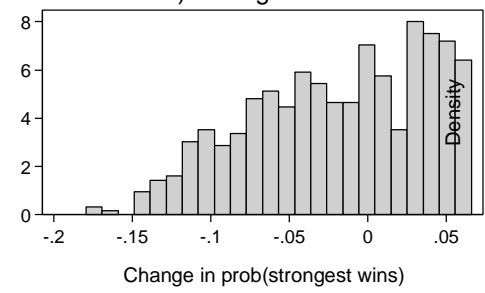

c) Strongest wins (zero duration contests)

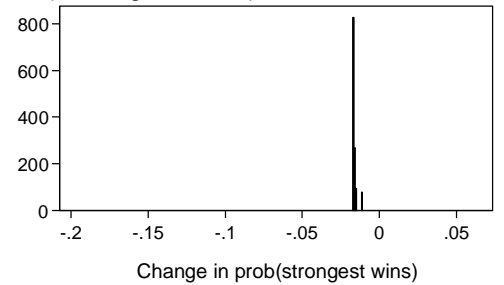

Fig. S4 Study 3: Distribution of the marginal effects of a one standard deviation change in the difference in strength on contest duration and the probability that the strongest contestants wins. The histograms are based on marginal effects computed from (a) Table S3, model 1, (b) Table S5, model 2, and (c) Table S5, model 5. 

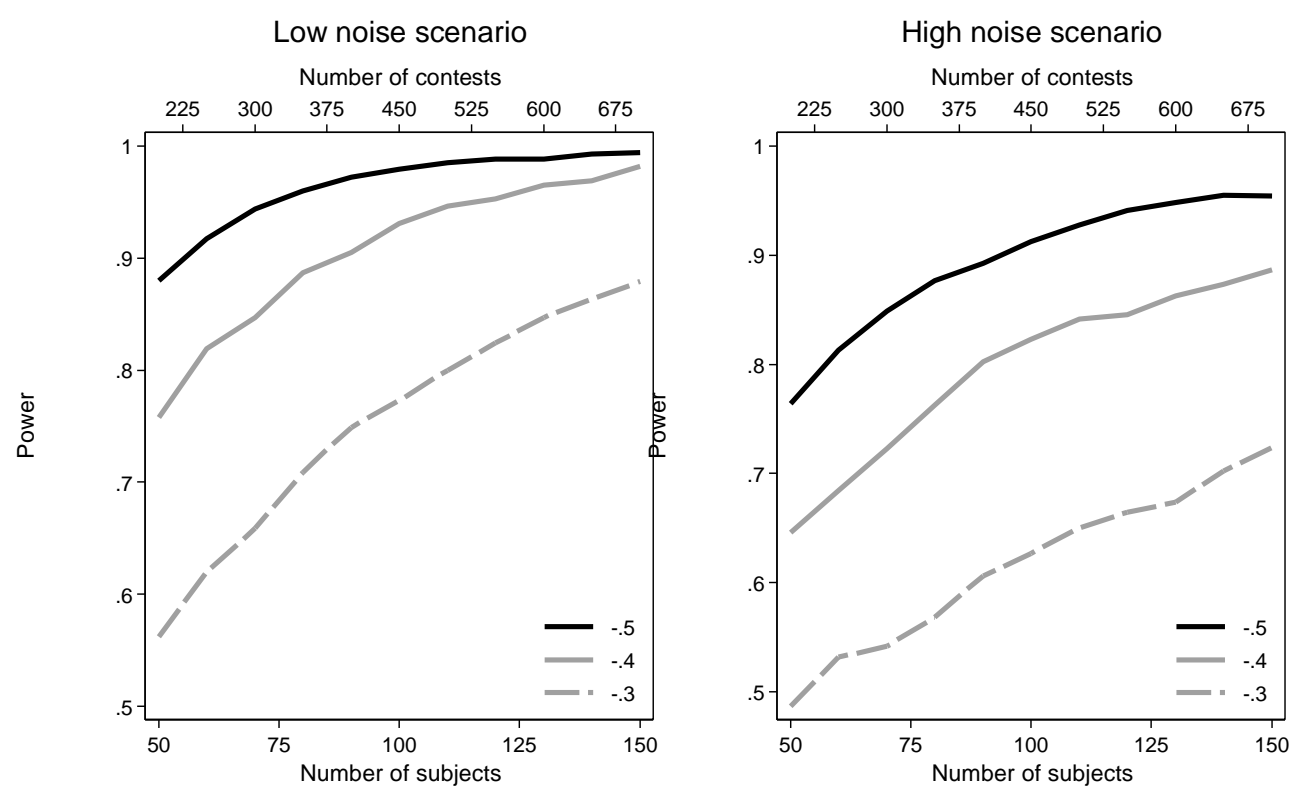

Fig. S5 Power as a function of coefficient size and sample size. Monte carlo simulations with 1,000 replications, based on a session size of 10 and the data generating process explained in the ESM methods description for Study 3.

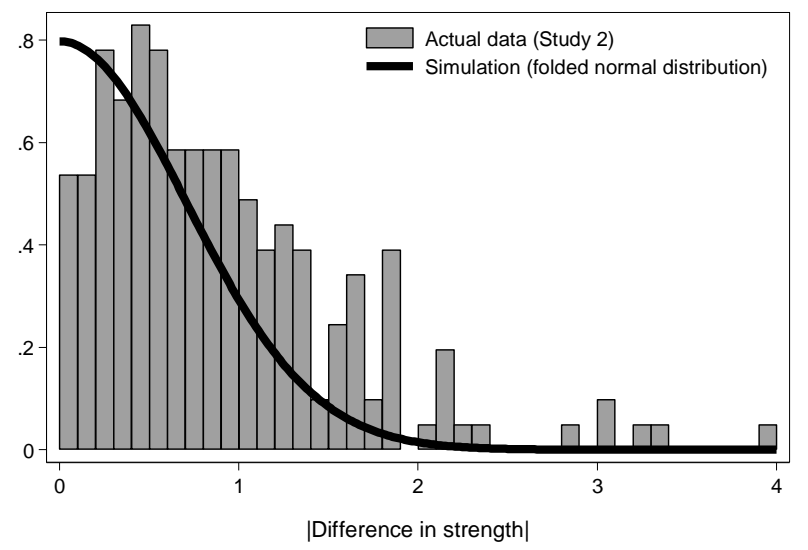

Fig. S6 Assumed data generating process for |Difference in strength|. Histogram of the strength differences in Study 2 overlaid with the density of the folded normal distribution. The monte carlo simulations for power calculations assume that strength is normally distributed and hence |Difference in strength| has a folded normal distribution (see ESM methods description for Study 3). 

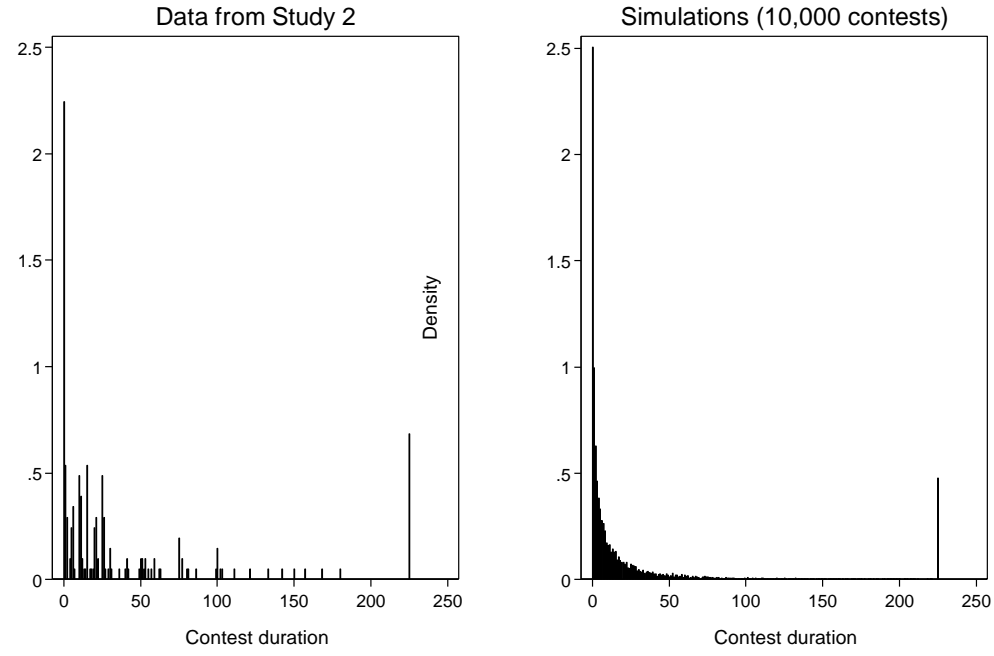

Fig. S7 Assumed data generating process for contest duration. Histograms of the contest durations in the Mutual Assessment Treatment in Study 2 and simulated data for 10,000 contests, assuming session size of 10 , coefficient size -.5 , and low noise (see ESM methods description for Study 3). 


\section{Tables}

Table S1 Descriptive statistics for Studies 2 and 4 (non-standardized, except strength).

\begin{tabular}{|c|c|c|c|c|c|c|c|c|c|c|c|c|}
\hline & \multicolumn{8}{|c|}{ Study 2} & \multicolumn{4}{|c|}{ Study 3} \\
\hline & \multicolumn{4}{|c|}{ MAT $(\mathrm{N}=42)$} & \multicolumn{4}{|c|}{ SAT $(N=24)$} & \multicolumn{4}{|c|}{ MAT (N=103) } \\
\hline & Mean & {$[95 \% \mathrm{CI}]$} & Min & Max & Mean & {$[95 \% \mathrm{CI}]$} & Min & Max & Mean & {$[95 \% \mathrm{CI}]$} & Min & Max \\
\hline Strength (composite measure, z-scored) & -.22 & $\begin{array}{l}-.47 ; \\
.03]\end{array}$ & -1.61 & 2.31 & -.001 & $\begin{array}{l}{[-.32 ;} \\
.31]\end{array}$ & -1.71 & 1.10 & .00 & $\begin{array}{l}{[-.14 ;} \\
.15]\end{array}$ & -1.31 & 2.01 \\
\hline Grip strength $(\mathrm{kg} / \mathrm{F})$ & 49.6 & $\begin{array}{l}{[47.05 ;} \\
52.13]\end{array}$ & 36 & 77 & 52.42 & $\begin{array}{l}{[47.57 ;} \\
57.25]\end{array}$ & 34 & 75 & 45.17 & $\begin{array}{l}{[43.62 ;} \\
46.71]\end{array}$ & 28 & 68 \\
\hline Chest strength $(\mathrm{kg} / \mathrm{F})$ & 50.79 & $\begin{array}{l}{[46.35 ;} \\
55.20]\end{array}$ & 20 & 90 & 53.04 & $\begin{array}{l}{[48.82 ;} \\
57.25]\end{array}$ & 35 & 70 & 37.47 & $\begin{array}{l}{[35 ;} \\
39.95]\end{array}$ & 12 & 83 \\
\hline Flexed biceps $(\mathrm{cm})$ & 35.5 & $\begin{array}{l}{[32.63 ;} \\
34.36]\end{array}$ & 27 & 40 & 33.43 & $\begin{array}{l}{[32.35} \\
34.51]\end{array}$ & 27.5 & 39.5 & 33.44 & $\begin{array}{l}{[32.86 ;} \\
34.03]\end{array}$ & 24.5 & 40 \\
\hline Self-reported strength $(0-100)^{*}$ & 45.57 & $\begin{array}{l}{[38.26 ;} \\
52.87]\end{array}$ & 2 & 95 & 55.88 & $\begin{array}{l}{[46.88 ;} \\
64.86]\end{array}$ & 10 & 90 & 51.40 & $\begin{array}{l}{[46.95 ;} \\
55.85]\end{array}$ & 0 & 100 \\
\hline Age (years) $* *$ & 22.83 & $\begin{array}{l}\text { [20.61; } \\
22.38]\end{array}$ & 19 & 30 & 21.5 & $\begin{array}{l}\text { [21.99; } \\
23.67]\end{array}$ & 19 & 27 & 25.49 & $\begin{array}{l}\text { [23.61; } \\
27.36]\end{array}$ & 19 & 76 \\
\hline Height $(\mathrm{cm})$ & $\begin{array}{l}184.1 \\
9\end{array}$ & $\begin{array}{l}{[182.55 ;} \\
185.82]\end{array}$ & 172 & 200 & $\begin{array}{l}182.3 \\
3\end{array}$ & $\begin{array}{l}{[179.22 ;} \\
185.44]\end{array}$ & 169 & 196 & $\begin{array}{l}184.0 \\
1\end{array}$ & $\begin{array}{l}{[182.77 ;} \\
185.26]\end{array}$ & 163 & 199 \\
\hline Weight (kg) & 79.92 & $\begin{array}{l}\text { [76.48; } \\
83.35]\end{array}$ & 63.3 & 103.2 & 77.23 & $\begin{array}{l}\text { [73.07; } \\
81.38]\end{array}$ & 57.1 & 97.10 & 79.75 & $\begin{array}{l}\text { [77.8; } \\
81.7]\end{array}$ & 60.5 & 108.9 \\
\hline BMI & 23.57 & $\begin{array}{l}{[22.57 ;} \\
24.57]\end{array}$ & 17.9 & 31.1 & 23.23 & $\begin{array}{l}{[22.06 ;} \\
24.40]\end{array}$ & 18.4 & 29.7 & 23.56 & $\begin{array}{l}{[23.02 ;} \\
24.09]\end{array}$ & 17.9 & 31.9 \\
\hline Risk tolerance $(0-10)$ & 6.47 & $\begin{array}{l}{[5.82 ;} \\
7.12]\end{array}$ & 2 & 10 & 6.20 & $\begin{array}{l}{[5.08 ;} \\
7.33]\end{array}$ & 0 & 10 & 6.12 & $\begin{array}{l}{[5.66 ;} \\
6.57]\end{array}$ & 1 & 10 \\
\hline
\end{tabular}

MAT: Mutual Assessment Treatment, SAT: Self-Assessment Treatment. CI: 95-percent confidence interval. The composite measure strength is the average of the standardized measures for grip strength, chest strength, flexed biceps, and self-reported strength. 
Table S2 Negative binomial regressions for the duration of contests (Mutual Assessment Treatment in Study 2).

\begin{tabular}{|c|c|c|c|c|c|c|c|c|}
\hline & Model 1 & Model 2 & Model 3 & Model 4 & Model 5 & Model 6 & Model 7 & Model 8 \\
\hline |Difference in strength| & $\begin{array}{l}-.481^{*} \\
(.259)\end{array}$ & & $\begin{array}{r}-1.029 * * * \\
(.276)\end{array}$ & & & $\begin{array}{r}-.470 * \\
(.257)\end{array}$ & & \\
\hline |Difference in height| & & $-.313^{*}$ & $-815^{* * *}$ & & & & & \\
\hline |Diff. strength x Diff. height| & & & $\begin{array}{r}.572 * * \\
(.225)\end{array}$ & & & & & \\
\hline |Difference in BMI| & & & & $\begin{array}{r}-.044 \\
(.127)\end{array}$ & & & & \\
\hline |Difference in risk tolerance| & & & & & $\begin{array}{r}-.076 \\
(.083)\end{array}$ & $\begin{array}{r}-.069 \\
(.083)\end{array}$ & & \\
\hline Stronger rival strength & & & & & & & $\begin{array}{r}-.547 * * \\
(.253)\end{array}$ & $\begin{array}{r}-.483^{*} \\
(.277)\end{array}$ \\
\hline Weaker rival strength & & & & & & & $\begin{array}{r}.273 \\
(.431)\end{array}$ & $\begin{array}{r}.286 \\
(.453)\end{array}$ \\
\hline Risk tolerance of stronger rival & & & & & & & & $\begin{array}{r}.137 * * * \\
(.052)\end{array}$ \\
\hline Risk tolerance of weaker rival & & & & & & & & $\begin{array}{r}.047 \\
(.058)\end{array}$ \\
\hline Taller rival height & & & & & & & & $\begin{array}{r}.026 \\
(.189)\end{array}$ \\
\hline Shorter rival height & & & & & & & & $\begin{array}{r}.592 * * \\
(.281)\end{array}$ \\
\hline Constant & $\begin{array}{r}4.041^{* * * *} \\
(.616) \\
\end{array}$ & $\begin{array}{r}3.650 * * * \\
(.580) \\
\end{array}$ & $\begin{array}{r}4.810^{* * * *} \\
(.731) \\
\end{array}$ & $\begin{array}{r}3.472 * * * \\
(.591) \\
\end{array}$ & $\begin{array}{r}3.615^{* * * *} \\
(.589) \\
\end{array}$ & $\begin{array}{r}4.181^{* * * *} \\
(.603) \\
\end{array}$ & $\begin{array}{r}3.878^{* * *} \\
(.661) \\
\end{array}$ & $\begin{array}{r}2.990^{* * * *} \\
(.677)\end{array}$ \\
\hline Tests for overdispersion $\left(\mathrm{H}_{0}:\right.$ alpha $\left.=\mathbf{0}\right)$ & & & & & & & & \\
\hline Alpha & $\begin{array}{r}2.764 * * * \\
(.640)\end{array}$ & $\begin{array}{r}2.790 * * * \\
(.624)\end{array}$ & $\begin{array}{r}2.676^{* * * *} \\
(.608)\end{array}$ & $\begin{array}{r}2.829 * * * \\
(.646)\end{array}$ & $\begin{array}{r}2.815 * * * \\
(.644)\end{array}$ & $\begin{array}{r}2.750 * * * \\
(.640)\end{array}$ & $\begin{array}{r}2.752 * * * \\
(.637)\end{array}$ & $\begin{array}{r}2.598 * * * \\
(.592)\end{array}$ \\
\hline $99 \%$ confidence interval & {$[1.52,5.01]$} & {$[1.56,4.96]$} & {$[1.49,4.80]$} & {$[1.57,5.09]$} & {$[1.56,5.07]$} & {$[1.51,5.00]$} & {$[1.51,4.99]$} & {$[1.44,4.67]$} \\
\hline LR-test $\chi^{2}(2)$ & 12157.07 & 12238.31 & 11572.91 & 12480.03 & 12293.88 & 11940.14 & 12085.64 & 10849.45 \\
\hline Observations & 205 & 205 & 205 & 205 & 205 & 205 & 205 & 205 \\
\hline
\end{tabular}

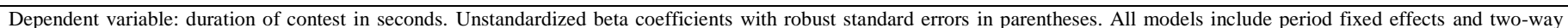

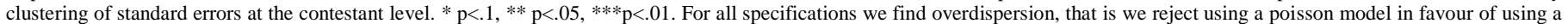
negative binomial model, both using the estimated confidence intervals for alpha (which account for clustering) and standard likelihood ratio tests (which cannot account for clustering). 
Table S3 Negative binomial regressions for the duration of contests (Mutual Assessment Treatment in Study 3).

\begin{tabular}{|c|c|c|c|c|c|c|c|c|}
\hline & Model 1 & Model 2 & Model 3 & Model 4 & Model 5 & Model 6 & Model 7 & Model 8 \\
\hline |Difference in strength| & $\begin{array}{r}-.043 \\
(.102)\end{array}$ & & $\begin{array}{c}.271 * * \\
(.138)\end{array}$ & & & $\begin{array}{r}-.039 \\
(.103)\end{array}$ & & \\
\hline \multirow[t]{2}{*}{ |Difference in height| } & & -.062 & $.224^{*}$ & & & & & \\
\hline & & $(.077)$ & $(.125)$ & & & & & \\
\hline \multirow[t]{2}{*}{ |Diff. strength x Diff. height| } & & & $-.278 * * *$ & & & & & \\
\hline & & & $(.093)$ & & & & & \\
\hline \multirow[t]{2}{*}{ |Difference in BMI| } & & & & .024 & & & & \\
\hline & & & & $(.065)$ & & & & \\
\hline \multirow[t]{2}{*}{ |Difference in risk tolerance| } & & & & & -.052 & -.051 & & \\
\hline & & & & & $(.042)$ & $(.042)$ & & \\
\hline \multirow[t]{2}{*}{ Stronger rival strength } & & & & & & & -.058 & -.062 \\
\hline & & & & & & & $(.128)$ & $(.122)$ \\
\hline \multirow[t]{2}{*}{ Weaker rival strength } & & & & & & & .014 & -.054 \\
\hline & & & & & & & $(.119)$ & $(.127)$ \\
\hline \multirow[t]{2}{*}{ Risk tolerance of stronger rival } & & & & & & & & $.071 *$ \\
\hline & & & & & & & & $(.038)$ \\
\hline \multirow[t]{2}{*}{ Risk tolerance of weaker rival } & & & & & & & & .054 \\
\hline & & & & & & & & $(.037)$ \\
\hline \multirow[t]{2}{*}{ Taller rival height } & & & & & & & & -.104 \\
\hline & & & & & & & & $(.094)$ \\
\hline \multirow[t]{2}{*}{ Shorter rival height } & & & & & & & & .057 \\
\hline & & & & & & & & $(.092)$ \\
\hline \multirow[t]{2}{*}{ Constant } & $3.550 * * *$ & $3.596 * * *$ & $3.338 * * *$ & $3.488^{* * *} *$ & $3.646^{* * * *}$ & $3.676^{* * * *}$ & $3.537 * * *$ & $2.806^{* * *}$ \\
\hline & $(.242)$ & $(.227)$ & $(.218)$ & $(.236)$ & $(.226)$ & $(.253)$ & $(.236)$ & $(.354)$ \\
\hline \multicolumn{9}{|l|}{ Tests for overdispersion $\left(\mathrm{H}_{0}:\right.$ alpha $\left.=0\right)$} \\
\hline \multirow[t]{2}{*}{ alpha } & $1.89 * * *$ & $1.89 * * *$ & $1.87 * * *$ & $1.89 * * *$ & $1.88 * * *$ & $1.88 * * *$ & $1.89 * * *$ & $1.83 * * *$ \\
\hline & $(.24)$ & $(.24)$ & $(.24)$ & $(.24)$ & $(.24)$ & $(.24)$ & $(.24)$ & $(.24)$ \\
\hline $99 \%$ confidence interval & {$[1.36 ; 2.62]$} & {$[1.36 ; 2.62]$} & {$[1.35 ; 2.59]$} & {$[1.36 ; 2.62]$} & {$[1.36 ; 2.61]$} & {$[1.36 ; 2.61]$} & {$[1.36 ; 2.62]$} & {$[1.31 ; 2.55]$} \\
\hline LR-test $\chi^{2}(2)$ & 34647.21 & 34608.36 & 34223.57 & 34673.28 & 34439.92 & 34403.72 & 34638.82 & 33044.11 \\
\hline
\end{tabular}

$\begin{array}{lllllllll}\text { Observations } & 651 & 651 & 651 & 651 & 651 & 651 & 651\end{array}$

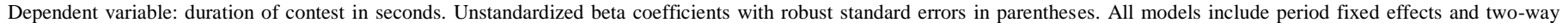

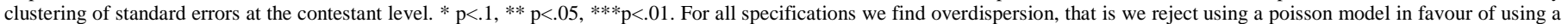
negative binomial model, both using the estimated confidence intervals for alpha (which account for clustering) and standard likelihood ratio tests (which cannot account for clustering). 
Table S4 Logistic regressions on whether the strongest contestant wins (Mutual Assessment Treatment in Study 2).

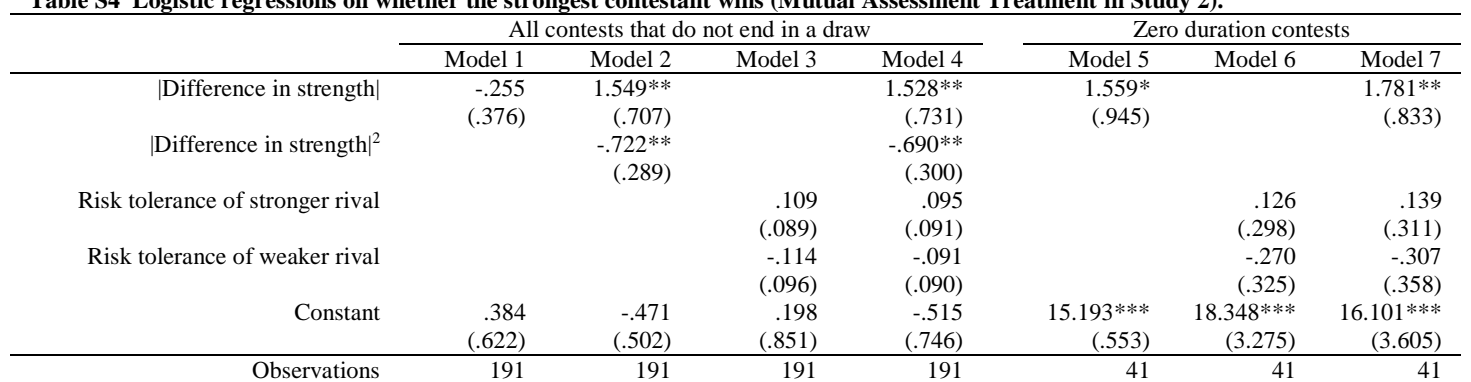

Dependent variable: dummy=1 (0) if strongest (weakest) contestant within a pair wins. Models 1-4 exclude 14 contests that ended in a tie. Models 5-7 focus on the 41 contests that ended immediately. Unstandardized beta coefficients with robust standard errors in parentheses. All models include period fixed effects and two-way clustering of standard errors at the contestant level. . ${ }^{*} \mathrm{p}<.1, * * \mathrm{p}<.05, * * * \mathrm{p}<.01$.

Table S5 Logistic regressions on whether the strongest contestant wins (Mutual Assessment Treatment in Study 3).

\begin{tabular}{|c|c|c|c|c|c|c|c|}
\hline & \multicolumn{4}{|c|}{ All contests that do not end in a draw } & \multicolumn{3}{|c|}{ Zero duration contests } \\
\hline & Model 1 & Model 2 & Model 3 & Model 4 & Model 5 & Model 6 & Model 7 \\
\hline |Difference in strenoth| $\left.\right|^{2}$ & $(.149)$ & $\begin{array}{r}(.404) \\
-358 * *\end{array}$ & & $\begin{array}{r}(.447) \\
-233\end{array}$ & & & \\
\hline Risk tolerance of stronger rival & & & $.250^{* * *}$ & $.247 * * *$ & & .209 & .211 \\
\hline & & & (.048) & $(.050)$ & & $(.132)$ & $(.136)$ \\
\hline Constant & -.264 & -.526 & .019 & -.026 & -.424 & -.113 & .134 \\
\hline & $(.326)$ & $(.369)$ & $(.471)$ & $(.517)$ & $(.781)$ & $(.886)$ & $(.978)$ \\
\hline Observations & 611 & 611 & 611 & 611 & 80 & 80 & 80 \\
\hline
\end{tabular}

Dependent variable: dummy=1 (0) if strongest (weakest) contestant within a pair wins. Models 1-4 exclude 40 contests that ended in a tie. Models 5-7 focus on the 85 contests that ended immediately ( 5 contests were predicted by period fixed effects and dropped). Unstandardized beta coefficients with robust standard errors in parentheses. All models include period fixed effects and two-way clustering of standard errors at the contestant level. . * $\mathrm{p}<.1, * * \mathrm{p}<.05, * * * \mathrm{p}<.01$ 
Table S6 Contest outcomes Self-Assessment Treatment vs Mutual Assessment Treatment in Study 2.

\begin{tabular}{|c|c|c|c|c|}
\hline \multirow[b]{3}{*}{ Dependent variable } & \multirow{2}{*}{\multicolumn{2}{|c|}{\begin{tabular}{|cr} 
Model 1 & Model 2 \\
Negative binomial regressions \\
\end{tabular}}} & Model 3 & Model 4 \\
\hline & & & \multicolumn{2}{|c|}{ Logit regressions } \\
\hline & \multicolumn{2}{|c|}{ Duration of contest in seconds } & \multicolumn{2}{|c|}{$\begin{array}{c}\text { Dummy whether strongest contestant } \\
\text { wins }\end{array}$} \\
\hline \multicolumn{5}{|l|}{ Main effects } \\
\hline SAT (baseline category) & - & - & - & - \\
\hline MAT & $\begin{array}{r}.664 \\
(.462)\end{array}$ & $\begin{array}{r}.469 \\
(.485)\end{array}$ & $\begin{array}{l}-.023 \\
(.482)\end{array}$ & $\begin{array}{r}-.996^{*} \\
(.550)\end{array}$ \\
\hline \multicolumn{5}{|c|}{ Effects for the Mutual Assessment Treatment } \\
\hline MAT x |Difference in strength| & $\begin{array}{l}-.458^{*} \\
(.260)\end{array}$ & & $\begin{array}{r}-.273 \\
(.369)\end{array}$ & $\begin{array}{r}1.428 * * \\
(.677)\end{array}$ \\
\hline MAT x $\mid$ Difference in strength $\left.\right|^{2}$ & & & & $\begin{array}{r}-.679 * * \\
(.272)\end{array}$ \\
\hline MAT x Stronger rival strength & & $\begin{array}{r}-.538 * * \\
(.263)\end{array}$ & & \\
\hline MAT x Weaker rival strength & & $\begin{array}{r}.229 \\
(.406)\end{array}$ & & \\
\hline \multicolumn{5}{|c|}{ Effects for the Self-Assessment Treatment } \\
\hline SAT $\mathrm{x} \mid$ Difference in strength $\mid$ & $\begin{array}{r}-.135 \\
(.252)\end{array}$ & & $\begin{array}{r}-.936^{*} \\
(.535)\end{array}$ & $\begin{array}{r}-1.939 * * \\
(.892)\end{array}$ \\
\hline SAT $x \mid$ Difference in strength $\left.\right|^{2}$ & & & & $\begin{array}{r}.531 \\
(.426)\end{array}$ \\
\hline SAT x Stronger rival strength & & $\begin{array}{l}-.941 \\
(.656)\end{array}$ & & \\
\hline SAT $x$ Weaker rival strength & & $\begin{array}{r}-.353 * * \\
(.180)\end{array}$ & & \\
\hline Constant & $\begin{array}{r}3.190^{* * * *} \\
(.693)\end{array}$ & $\begin{array}{r}3.243^{* * * *} \\
(.663)\end{array}$ & $\begin{array}{r}.377 \\
(.678)\end{array}$ & $\begin{array}{r}.574 \\
(.727)\end{array}$ \\
\hline Observations & 311 & 311 & 293 & 293 \\
\hline $\begin{array}{l}\text { Model 1: Negative binomial regressio } \\
\text { 2-3: Logistic regressions on whether } \\
\text { contestant within a pair wins; exclude } \\
\text { in parentheses. All models include p } \\
\text { |Difference in strength| is interacted } \\
\text { Treatment and SAT the interaction wi }\end{array}$ & $\begin{array}{l}\text { e duration of c } \\
\text { ngest contesta } \\
\text { ts ending in a } \\
\text { xed effects an } \\
\text { condition, w }\end{array}$ & $\begin{array}{l}\text {; dependent } \\
\text {; depender } \\
\text { Jnstandardi } \\
\text { way cluster } \\
\text { IAT indica }\end{array}$ & $\begin{array}{l}\text { duration of contes } \\
\text { coefficients with } r \\
\text { andard errors at } t \\
\text { teraction with the }\end{array}$ & $\begin{array}{l}\text { s., Models } \\
\text { (weakest) } \\
\text { lard errors } \\
\text { nt level. . } \\
\text { ssessment }\end{array}$ \\
\hline
\end{tabular}


Table S7 Logistic regressions on whether the tallest contestant wins (Mutual Assessment Treatment).

\begin{tabular}{|c|c|c|c|c|c|c|c|c|}
\hline & \multicolumn{4}{|c|}{$\begin{array}{r}\text { Study } 2 \\
\end{array}$} & \multicolumn{4}{|c|}{$\begin{array}{r}\text { Study } 3 \\
\end{array}$} \\
\hline & Model 1 & Model 2 & Model 3 & Model 4 & Model 1 & Model 2 & Model 3 & Model 4 \\
\hline Difference in & .187 & -.453 & & .185 & .044 & -.109 & & .036 \\
\hline height| & $(.215)$ & $(.742)$ & & $(.233)$ & $(.127)$ & $(.302)$ & & $(.123)$ \\
\hline Difference in & & .216 & & & & & & \\
\hline height|^2 & & $(.225)$ & & & & .047 & & \\
\hline Risk tolerance of & & & .061 & .068 & & $(.071)$ & & \\
\hline taller rival & & & $(.078)$ & $(.083)$ & & & & \\
\hline Risk tolerance of & & & $-.194 *$ & $-.191 *$ & & & $.174 * * *$ & $.174 * * *$ \\
\hline shorter rival & & & $(.106)$ & $(.109)$ & & & $(.057)$ & (.057) \\
\hline Constant & -.414 & -.075 & .673 & .381 & & & $-.252 * * *$ & $-.252 * * *$ \\
\hline & $(.540)$ & $(.678)$ & $(.935)$ & $(.851)$ & & & $(.059)$ & $(.059)$ \\
\hline Observations & 181 & 181 & 181 & 181 & 590 & 590 & 590 & 590 \\
\hline
\end{tabular}

Dependent variable: dummy=1 (0) if tallest (shortest) contestant within a pair wins. Contests where rivals had equal height and contests that ended in a tie were excluded. Unstandardized beta coefficients with robust standard errors in parentheses. All models include period fixed effects and two-way clustering of standard errors at the contestant level. . $* \mathrm{p}<.1, * * \mathrm{p}<.05, * * *<0.01$.

Table S8 Logistic regressions on whether the leanest contestant wins (Mutual Assessment Treatment).

\begin{tabular}{|c|c|c|c|c|c|c|c|c|}
\hline & \multicolumn{4}{|c|}{\begin{tabular}{|l} 
Study 2 \\
\end{tabular}} & \multicolumn{4}{|c|}{ Study 3} \\
\hline & Model 1 & Model 2 & Model 3 & Model 4 & Model 1 & Model 2 & Model 3 & Model 4 \\
\hline Difference in & .050 & .408 & & -.011 & .039 & .352 & & -.033 \\
\hline BMI & $(.177)$ & $(.599)$ & & $(.182)$ & $(.134)$ & $(.294)$ & & $(.116)$ \\
\hline Difference in & & -.116 & & & & -.096 & & \\
\hline$\left.\mathrm{BMI}\right|^{\wedge} 2$ & & $(.172)$ & & & & $(.086)$ & & \\
\hline Risk tolerance of & & & .128 & .128 & & & $.188 * * *$ & $.189 * * *$ \\
\hline leaner rival & & & $(.086)$ & $(.087)$ & & & $(.052)$ & $(.052)$ \\
\hline Risk tolerance of & & & -.162 & -.163 & & & $-.234 * * *$ & $-.235 * * *$ \\
\hline heavier rival & & & $(.099)$ & $(.100)$ & & & $(.068)$ & $(.068)$ \\
\hline Constant & .501 & .316 & .810 & .826 & $.483 *$ & .342 & .815 & .852 \\
\hline & $(.673)$ & $(.754)$ & $(1.142)$ & $(1.171)$ & $(.286)$ & $(.295)$ & $(.552)$ & $(.537)$ \\
\hline Observations & 191 & 191 & 191 & 191 & 611 & 611 & 611 & 611 \\
\hline
\end{tabular}

Table S9 Descriptive statistics for the personality feature ratings in Study 4 (unstandardized).

\begin{tabular}{|c|c|c|c|c|}
\hline Variable & $\begin{array}{c}\text { Number of } \\
\text { raters }\end{array}$ & $\begin{array}{c}\text { Mean [std.dev] } \\
N=42\end{array}$ & Min & Max \\
\hline Prone to aggression & 94 & $4.28[0.37]$ & 3.68 & 5.10 \\
\hline Used to getting his way & 89 & $4.53[0.39]$ & 3.76 & 5.64 \\
\hline A valuable friend & 92 & $4.78[0.26]$ & 4.16 & 5.17 \\
\hline Intelligent & 100 & $4.75[0.28]$ & 3.96 & 5.18 \\
\hline
\end{tabular}

Ratings for all 42 pictures of the Mutual Assessment Treatment. Each variable encodes the mean rating of a particular picture along the personality feature and can take on values between 1 (extremely unlikely to fit the person depicted) and 7 (extremely likely to fit the person depicted). The second column lists the number of raters who were randomly assigned to rating the personality feature. 
Table S10 Correlations of average personality feature ratings among each other and with strength (standardized).

\begin{tabular}{|c|c|c|c|c|c|}
\hline & Variable & Prone to aggression & Used to getting his way & A valuable friend & Intelligent \\
\hline \multirow[t]{5}{*}{ Study 4} & Prone to aggression & 1 & & & \\
\hline & Used to getting his way & $.673^{* * *}$ & 1 & & \\
\hline & A valuable friend & $-.405^{* * * *}$ & .134 & 1 & \\
\hline & Intelligent & $-.601 * * *$ & -.161 & $.762 * * *$ & 1 \\
\hline & Strength & $.631 * * *$ & $.493 * * *$ & $-.276^{*}$ & -.249 \\
\hline $\begin{array}{r}\text { Repliaction study } \\
\text { (Study 3) }\end{array}$ & Strength & .021 & & & \\
\hline
\end{tabular}

Table S11 Potential mediators of the effect of differences in strength on contest duration in the Mutual Assessment Treatment (Studies 2 \& 4).

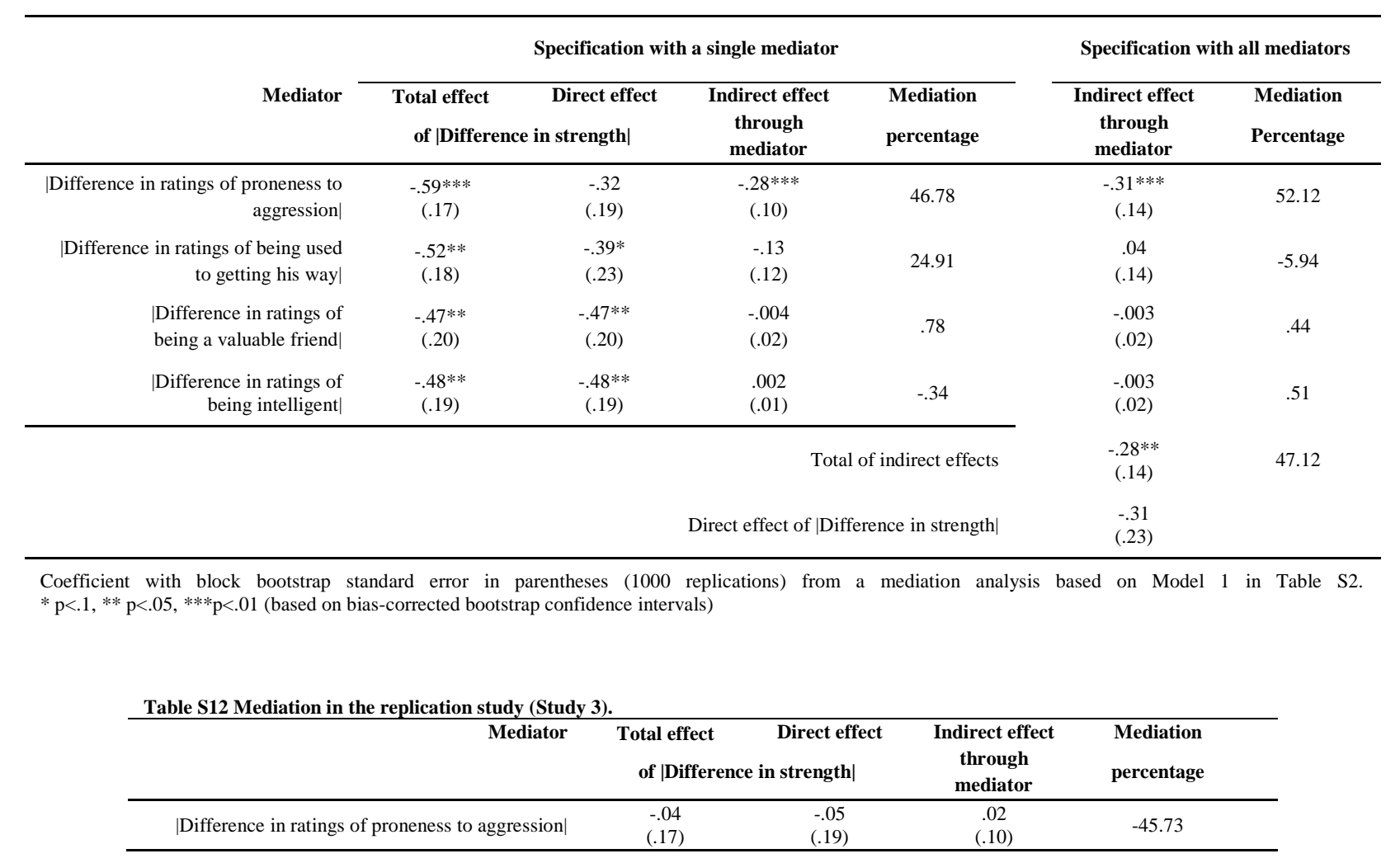




\section{References}

Ball, S., Eckel, C., \& Heracleous, M. (2010). Risk aversion and physical prowess: Prediction, choice and bias. Journal of Risk and Uncertainty, 41(3), 167-193

Borghans, L., Duckworth, A. L., Heckman, J. J., \& Ter Weel, B. (2008). The economics and psychology of personality traits. Journal of Human Resources, 43(4), 972-1059.

Cameron, A. C., J.B. Gelbach, and D.L. Miller. 2011. Robust inference with multiway clustering. Journal of Business and Economic Statistics 29(2): 238-249.

Charness, G., Gneezy, U., \& Halladay, B. (2016). Experimental methods: Pay one or pay all. Journal of Economic Behavior \& Organization 131, 141-150.

Dohmen, T., Falk, A., Huffman, D., Sunde, U., Schupp, J., \& Wagner, G. G. (2011). Individual risk attitudes: Measurement, determinants, and behavioral consequences. Journal of the European Economic Association, 9(3), 522-550.

Hilbe, J.M. (2011). Negative Binomial Regression. $2^{\text {nd }}$ edition, Cambridge, U.K.: Cambridge University Press.

Kohler, U., Karlson, K.B., \& Holm, A. (2011). Comparing Coefficients of nested nonlinear probability models. The Stata Journal, 11(3), 420-438.

Sell, A., Tooby, J., \& Cosmides, L. (2009a). Formidability and the logic of human anger. Proceedings of the National Academy of Sciences, 106(35), 15073-15078.

Sell, A., Cosmides, L., Tooby, J., Sznycer, D., von Rueden, C., \& Gurven, M. (2009b). Human adaptations for the visual assessment of strength and fighting ability from the body and face. Proceedings of the Royal Society of London B: Biological Sciences, 276(1656), 575-584.

Taylor, P. W., \& Elwood, R. W. (2003). The mismeasure of animal contests. Animal Behaviour, 65(6), 1195-1202. 
Yoo, H.I. (2017). VCE2WAY: Stata module to adjust a Stata command's standard errors for two-way clustering, Statistical Software Components Archive S458311, Boston College Department of Economics. 